\title{
Bronze Age Swordsmanship: New Insights from Experiments and Wear Analysis
}

\author{
Raphael Hermann $^{1}$ (D) - Andrea Dolfini ${ }^{2}$ (D) Rachel J. Crellin $^{3}$ (D) \\ Quanyu Wang ${ }^{4}$ (D) Marion Uckelmann ${ }^{5}$
}

Published online: 17 April 2020

(C) The Author(s) 2020

\begin{abstract}
The article presents a new picture of sword fighting in Middle and Late Bronze Age Europe developed through the Bronze Age Combat Project. The project investigated the uses of Bronze Age swords, shields, and spears by combining integrated experimental archaeology and metalwork wear analysis. The research is grounded in an explicit and replicable methodology providing a blueprint for future experimentation with, and wear analysis of, prehistoric copper-alloy weapons. We present a four-step experimental methodology including both controlled and actualistic experiments. The experimental results informed the wear analysis of 110 Middle and Late Bronze Age swords from Britain and Italy. The research has generated new understandings of prehistoric combat, including diagnostic and undiagnostic combat marks and how to interpret them; how to hold and use a Bronze Age sword; the degree of skill and training required for proficient combat; the realities of Bronze Age swordplay including the frequency of blade-on-blade contact; the body parts and areas targeted by prehistoric sword fencers; and the evolution of fighting styles in Britain and Italy from the late 2 nd to the early 1 st millennia BC.

All primary data discussed in the article are available as supplementary material (Appendix) so as to allow scrutiny and validation of the research results.
\end{abstract}

Keywords European Bronze Age · Experimental archaeology · Metalwork wear analysis · Warfare and violence $\cdot$ Combat archaeology

Electronic supplementary material The online version of this article (https://doi.org/10.1007/s10816-02009451-0) contains supplementary material, which is available to authorized users.

Raphael Hermann

raphael.hermann@uni-goettingen.de

Extended author information available on the last page of the article 


\section{Introduction}

The last two decades have witnessed a substantial change in the study of interpersonal violence in prehistoric and preliterate societies. Spearheaded by Keeley's seminal monograph War before Civilization (1996), and aided by the new cultural and political milieu that followed the end of the Cold War, archaeologists and anthropologists have increasingly turned their attention to the nature and social significance of sanctioned aggression and warfare (Fry 2013; Otterbein 1997, 2004). In the field of European Bronze Age studies, this novel disciplinary interest has intersected longstanding research strands investigating warrior burials, hoarding practices, fortified settlements, martial imagery on rock art, osteological markers of injury, and weapon studies (Dolfini et al. 2018; Horn and Kristiansen 2018; Kristiansen 2018; Kristiansen and Larsson 2005; Kristiansen and Suchowska-Ducke 2015; Molloy 2017; Vandkilde 2013). The latter had long focused on one of the most iconic inventions of the Bronze Age world: the sword.

The new awareness that intergroup violence may have played a major role in the social transformations of Bronze Age Europe has had an invigorating effect on the discipline, spurring an array of specialist studies that investigated early metal weapons and armour by integrated archaeological and scientific analysis. In continuity with previous developments, the sword has enjoyed pride of place within this fastdeveloping research strand, somewhat overshadowing similar lines of enquiry into Bronze Age halberds, spears, and shields (Anderson 2011; Horn 2013, 2014, 2017; Lull et al. 2017; Molloy 2009; O'Flaherty 2007, O'Flaherty et al. 2011; Uckelmann 2011, 2012). Two principal methods have been employed, jointly or otherwise, to research how swords might have been used in prehistory: experimental archaeology and metalwork wear analysis.

Sword experiments are normally carried out with bespoke bronze replicas of the objects to be tested. They fall into two overarching categories: laboratory tests and field tests. Laboratory tests, such as those conducted by Bridgford (1997, 2000), offer the distinctive advantage of being more controllable and easier to record than those carried out in the field. They normally make use of drop testers or other mechanical devices, which allow excellent control of variables and good understanding of wear formation processes (Crellin et al. 2018). However, they offer limited scope for reproducing the complexity of human gesture. The problem is especially acute for swordsmanship, which is predicated upon the human body and the weapon working together, powered by fine motor skills and experiential knowledge (Molloy 2008).

Field experiments may appear to overcome this weakness. In experiential tests such as those conducted by Molloy (2006, 2007, 2008) and Gentile and van Gijn (2019), the human body is placed at the centre of the experiment. By allowing combatants to enact complex and 'realistic' fighting sequences, such tests provide an opportunity to correlate the mechanical properties of the weapons with the biomechanical properties of their bearers (Molloy 2008: 118). However, this is achieved at the expense of control over the experiment's many variables including wear formation (Gentile and van Gijn 2019: 131; Schenck 2011: 87-88). A further limitation of experiential tests is that they need to be grounded in a predetermined body of knowledge, which is normally provided by medieval and post-medieval fencing manuals. These, however, often contain cryptic or partial information, whose interpretation is far from straightforward 
(Forgeng and Kiermayer 2007; Molloy 2008). Moreover, European fencing manuals arose out of specific historical contexts determining the correct way (or indeed ways) in which swords had to be used, by whom, and in which encounters and settings. As Melheim and Horn (2014) perceptively argued, drawing on Mauss' (1973) notion of les techniques du corps, learning to use a weapon involves the incorporation of socially specific bodily techniques. We cannot presume that Bronze Age bodies and medieval/ Renaissance bodies would act in the same ways while fighting because fighting is a socially constituted activity, which is predicated upon a corpus of embodied knowledge unique to each society (Crellin et al. 2018). Finally, one must note that bronze and steel greatly differ in their material properties. This consideration provides a further obstacle to interpreting prehistoric swordsmanship in light of historic fencing styles.

To some extent, the shortcomings of both laboratory and field tests can be tempered by investigating the combat marks visible on prehistoric swords through metalwork wear analysis (MWA). This analytical method centres upon the microscopic observation of the manufacturing and use marks visible on ancient copperalloy artefacts (Dolfini and Crellin 2016; Gutiérrez Sáez and Martín Lerma, 2015). Despite its limited time depth, MWA has had a significant impact on Bronze Age weapon studies. For instance, it has overturned undemonstrated assumptions about the purely symbolic value of early weapons and has generated terrific new insights into their uses (e.g. Horn 2013, 2014, 2017; O'Flaherty et al. 2011). Despite its centrality to weapon studies, however, MWA relies on experimentation to elucidate prehistoric wear formation. This brings us back to the need to codify meaningful yet formalised tests with replica weapons and to cross-reference experimental and archaeological combat marks to generate credible interpretations (Crellin et al. 2018: 291).

With these problems in mind, in 2013, we launched the Bronze Age Combat Project, coordinated by one of the authors (AD). The project sought to investigate uses of Bronze Age swords, shields, and spears based on integrated MWA and replica weapon tests. The aim of the project was to understand how prehistoric bronze weapons were used, in what kinds of combat situations, and with what weapon strikes and bodily engagements. One of the project's main objectives was to explore the possibility of linking distinctive combat marks with specific uses of the weapons including strikes, parries, stabs, and throws. At a broader level, we wanted to gain a firm foothold into Bronze Age fighting practices including issues of weapon training, skill, and spatial/ temporal variation in combat practices. A related objective was to develop a reflexive research methodology allowing new knowledge to arise from the critical nexus between controlled weapon experiments, experiential combat tests and the wear analysis of archaeological and experimental weapons.

In this paper, we present results of our sword tests and wear analysis. 'Materials and Methods' investigates the material properties of the experimental and archaeological swords and discusses the research methodology including weapon testing and MWA. 'Data Analysis' presents the wear marks generated during the sword tests vis-à-vis those observed on Bronze Age swords from Britain and Italy. 'Discussion' discusses the new knowledge generated by weapon testing and MWA including how to hold a Bronze Age sword, how to fight with it and how swordsmanship changed from the 2nd to the early 1st millennium BC. Finally, 'Conclusion' summarises the research results and suggests further avenues for enquiry. 
The article is solely concerned with our sword tests and wear analysis. Further data and reflections concerning the Bronze Age Combat Project are published (or will be published) elsewhere. In particular, Hermann et al. (2019) outline project aims and structure; Crellin et al. (2018) critique the experimental methodology; and Hermann et al. (2020) provide an unabridged account of all weapon experiments. The spear and shield tests (and related MWA) will be discussed in Crellin et al. (in preparation) and Uckelmann et al. (in preparation).

\section{Materials and Methods}

To gain new insights into prehistoric swordsmanship, and to escape from the tyranny of the laboratory tests versus field tests dichotomy (see above), we grounded our research methodology in an innovative four-step approach. First, we conducted a set of controlled weapon tests in which replica Bronze Age swords were tested in single-strike actions (e.g. a single slash or stab) against other swords, spears, and shields made of wood, leather, and bronze. Secondly, helped by Historic European Martial Arts practitioners, we designed bespoke experiential (or 'actualistic') tests by adapting combat sequences drawn from the Commentary by Andre Lignitzer on Sword and Buckler, a fifteenth century fencing manual (Farrell 2012), to Bronze Age sword-and-shield combat. Thirdly, we carried out MWA on the swords, spears, and shields used for both controlled and experiential tests. Fourthly, we conducted MWA on a sample of Middle and Late Bronze Age swords from Britain and Italy and cross-referenced the marks observed on them with the marks generated experimentally, thereby grounding our interpretations in a knowable body of evidence. Details of our research methodology are provided below.

\section{The Replica Swords: Archaeology and Manufacturing Process}

All swords and spears used in our project, as well as the bronze and leather shields, were made by Neil Burridge, a traditional bronzesmith (www.bronze-age-craft.com). Jake Newport, a skilled amateur woodcarver, made the wooden shield using purposemade bronze tools. Burridge cast and prepared seven swords based on the following British and continental templates: one Middle Bronze Age Group IV rapier, c. 13001150 BC; one European continental Vollgriffschwert classified under Kemenczei's type S, c. 1200-1000 BC; one type Wilburton sword, c. 1150-975 BC; one Carp's Tongue sword, c. 950-800 BC; and three Ewart Park swords, c. 925-800 BC (Burgess and Colquhoun 1988; Kemenczei 1991). All swords were made from 12\% tin bronze alloy; they were subjected to a single cycle of work-hardening and were mechanically sharpened. Finally, oak hilt plates and pommels were added to all swords except the Vollgriffschwert specimen, which had the hilt and pommel cast in solid bronze (Fig. 1). We thought it useful to select a variety of sword types displaying significant differences in weight, balance, blade length, and blade geometry, for this would enable us to test the combat capabilities of different weapons, as well as their limitations.

Replicating these objects involved in-depth research into the manufacturing technology, alloy composition, and post-casting treatment of Bronze Age swords. The last two factors were judged to be of particular consequence because, even within a self- 
a

b
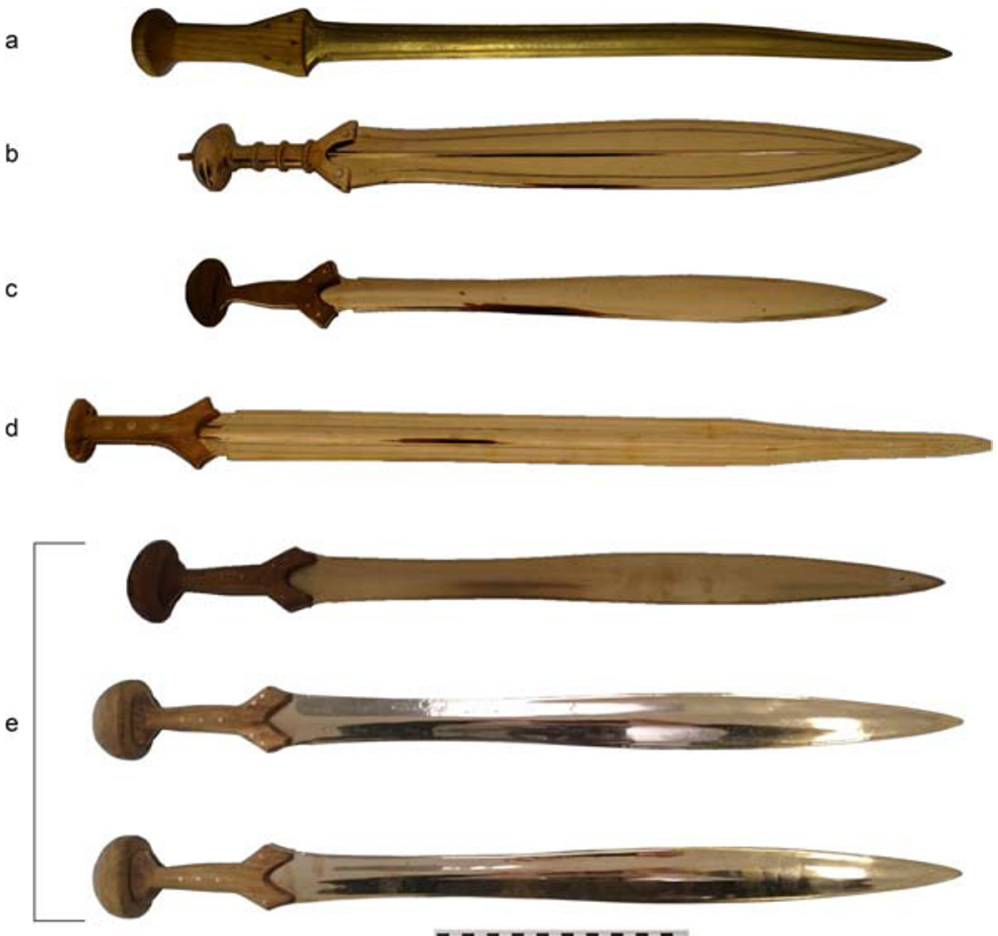

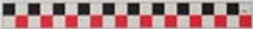

Fig. 1 a Group IV rapier $(658 \mathrm{~mm}, 565.0 \mathrm{~g})$. b Kemenczei type S Vollgriffschwert $(595 \mathrm{~mm}, 938.2 \mathrm{~g})$. c Wilburton type sword (562 mm, $511.5 \mathrm{~g}$ ). d Carp's Tongue type sword (745 mm, $761.5 \mathrm{~g}$ ). e Ewart Park type sword, the two nearest the bottom were used for the actualistic tests (top $658 \mathrm{~mm}, 701.4 \mathrm{~g}$; middle $696 \mathrm{~mm}$, $753.0 \mathrm{~g}$; bottom $695 \mathrm{~mm}, 752.1 \mathrm{~g}$ )

contained area and period, prehistoric swords show a wide variety of alloy compositions and post-casting treatments (see below). To reduce the variability inherent in the archaeological record, our sword replication process entailed several informed decisions, which we discussed with Neil Burridge. First, we decided to have all swords cast using $12 \%$ tin bronze. This alloy sits near the higher end of the spectrum documented for Bronze Age swords in Northern and Central Europe and Britain (see Bunnefeld 2016; Mödlinger 2011a, b; Northover 1988) but is also common in Italian swords, particularly those from Olmo di Nogara, which make up over $50 \%$ of the Italian specimens analysed for this project (Angelini et al. 2003). The alloy was selected as it improved the quality of the cast and reduced the risk of potentially dangerous defects developing within the objects. It is also the alloy with which Burridge is most familiar. All swords were cast with the same alloy composition to avoid introducing further variables into the experiment (Dolfini and Collins 2018). We deliberately chose not to add any lead to the replica swords, although lead is sometimes found in British and European continental swords from the Late Bronze Age (Mödlinger 2011b; Northover 1988). Lead is insoluble in copper and usually concentrates between the grains in copper alloys. As such, its presence effectively weakens the weapons. Gentile and van Gijn's study has shown that a small quantity of lead in copper alloys has no drastic influence on the formation of wear marks (2019: 139). 
Secondly, we relied on a smithing technique of Burridge's own design to workharden the blade edges. This involved a single cycle of expert edge hammering using a bronze hammer and anvil, followed by mechanical sharpening to a razor finish. All swords were worked and finished in the same way. Whereas the swords made by Burridge looked like excellent replicas of Bronze Age weapons, we needed to know if they were such in terms of microstructure and edge hardness, as these parameters may affect functionality and wear formation (Soriano-Llopis and Gutiérrez-Sáez 2009). Hence, upon completing the sword tests and MWA, we took cross-sections from the cutting edge to the centre of the blade of four replica swords for compositional, microstructural, and microhardness testing (sample size $1 \times 2 \mathrm{~cm}$ ).

The samples (named SW1-4) were mounted in epoxy resin, ground, and polished using diamond paste to a finish of $1 \mu \mathrm{m}$. They were examined with a Zeiss AXIOVERT 100A microscope for the metallographic study, and a Hitachi S-3700N variable pressure scanning electron microscope (SEM) equipped with energydispersive X-ray spectrometry (EDX) for compositional analysis. The SEM-EDX analyses were run at an accelerating voltage of $20 \mathrm{kV}$ at low vacuum of $50 \mathrm{~Pa}$ and working distance of $10 \mathrm{~mm}$.

The samples were found to have a tin content of 12.9-14.2\%, higher than that in the original charge. Faoláin and Northover (1998) have reported slightly exaggerated tin contents in experimentally cast swords, measured by XRF analysis, compared to the original charges. Wang and Ottaway (2004), on the other hand, measured the tin contents of their experimental casts by ICP-OES, with results close to the nominal bronze composition. It is presently unclear if higher-than-expected tin content in our casts had resulted from a weighing error in the original charge or is a function of the SEM-EDX analysis.

The samples were subjected to microhardness testing using an Indentec ZHV $\mu-\mathrm{M}$ tester. For each specimen, five points were tested from the cutting edge to the centre of the blade, with 150-300 $\mu \mathrm{m}$ intervals. The mean value and standard deviation for each sample are listed in Table 1. Overall, there is no clear increase in hardness values from blade centre to the cutting edge, although there are noticeable variations in the five points tested on each specimen.

Table 1 Vickers hardness (HV) and standard deviation (s.d.) values of the experimental swords vis-à-vis the $\mathrm{HV}$ values of metal sheets left at different states(point 1 is in the centre of the blade, point 5 near the cutting edge). The original charge of all samples contained $12 \% \mathrm{Sn}$ and $88 \% \mathrm{Cu}$

\begin{tabular}{|c|c|c|c|c|c|c|c|}
\hline \multirow[t]{2}{*}{ Sample } & \multirow{2}{*}{$\begin{array}{l}\text { SW1 } \\
\text { Cold-worked }\end{array}$} & \multirow{2}{*}{$\begin{array}{l}\text { SW2 } \\
\text { Cold-worked }\end{array}$} & \multirow{2}{*}{$\begin{array}{l}\text { SW3 } \\
\text { Cold-worked }\end{array}$} & \multirow{2}{*}{$\begin{array}{l}\text { SW4 } \\
\text { Cold-worked }\end{array}$} & \multicolumn{3}{|c|}{ Sheet metal } \\
\hline & & & & & As-cast & Annealed & Cold-worked \\
\hline Mean HV & 153 & 142 & 165 & 180 & 139 & 137 & 164 \\
\hline s.d. & 20 & 10 & 27 & 42 & 8 & 9 & 7 \\
\hline Point 1 & 160 & 147 & 193 & 198 & & & \\
\hline Point 2 & 138 & 130 & 177 & 180 & & & \\
\hline Point 3 & 140 & 135 & 129 & 185 & & & \\
\hline Point 4 & 185 & 141 & 145 & 122 & & & \\
\hline Point 5 & 142 & 155 & 180 & 217 & & & \\
\hline
\end{tabular}


Subsequently, the samples were etched using alcoholic ferric chloride to reveal their metallographic structures. All samples were found to have dendritic structures with little distortion: SW1 features a normal structure of $(\alpha+\delta)$ eutectoids, while $(\alpha+\delta)$ eutectoids in SW2-4 appear to be unusually concentrated on the boundaries of the $\alpha$ phase. This indicates that SW2-4 cooled at a faster rate than SW1 (Avner, 1974; Scott 1991). Samples from SW1-2 are very porous but otherwise differ in terms of pore size
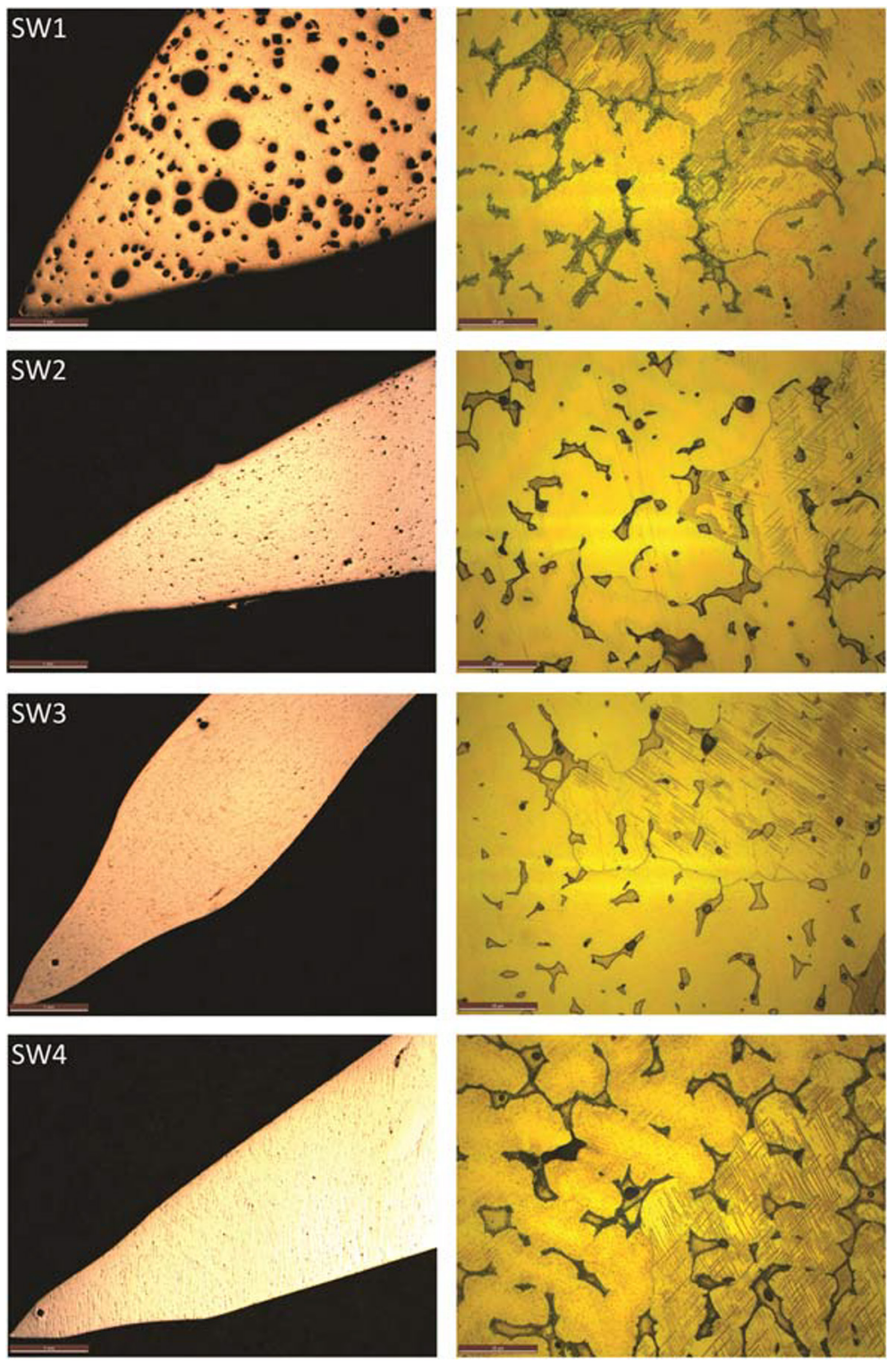

Fig. 2 Photomicrographs of the replica sword samples. Left column (unetched, low magnification; scale bar = $1 \mathrm{~mm}$ ): samples SW1 and SW2 showing porous structure and SW3 and SW4 showing dense structure. Right column (etched with alcoholic $\mathrm{FeCl}_{3}$ solution, high magnification; scale bar $=50 \mu \mathrm{m}$ ): all samples showing slip lines indicating cold-working 
(much larger in SW1 than SW2), while samples from SW3-4 are dense (Fig. 2). Overall, all swords examined had undergone some $10 \%$ thickness reduction by coldworking.

Most British Bronze Age swords analysed to date contain 7-14\% Sn, with added lead in some of them. Their hardness values lie between 100 and $200 \mathrm{HV}$ on the Vickers scale, and their microstructures include as-cast, cold-worked, partly recrystallised, fully recrystallised, and recrystallised and cold-worked objects. Thickness reduction ranges from none to over 50\% (Allen et al. 1970; Bridgford 2000; Brown and Blin-Stoyle 1959; Faoláin and Northover 1998; Northover 1988; Northover and Bridgford 2002). Such extreme diversity in alloy composition, microstructure, and hardness values is also found in swords from continental Europe (Bunnefeld 2016; Koui et al. 2006; Mödlinger 2011a, b; Molloy 2018). This strongly suggests that Bronze Age sword production did not follow a standardised manufacturing process, not even within a single region and period. It appears that swords, as much as other bronze tools and weapons, were manufactured based on the smith's technical skill and experience, in relationship to the material properties of the metal and cultural notions of what a finished sword should be like (Kuijpers 2018a, 2018b).

The compositional, microstructural, and microhardness analyses demonstrate that our replica swords fall within the technical parameters of Middle and Late Bronze Age swords from the Britain and compare well with continental European specimens, too. The high degree of variation witnessed in prehistoric bronze weapons suggests that any meaningful replication process must be predicated upon informed choices concerning the alloy composition, edge hardening, and thickness reduction of the original cast blanks. As a result, the replicas will compare well with certain Bronze Age swords and less well with others. This is a function of the diverse archaeological record. While further research is needed to understand how differences in alloy composition and edge hardening may affect sword performance in combat experiments (building on SorianoLlopis and Gutiérrez-Sáez 2009), we are satisfied that our replicas provide a good match for the archaeological swords, thus validating the test results and MWA discussed below.

\section{Controlled Weapon Tests}

The controlled weapon tests (CWTs) were designed to recreate prehistoric one-on-one combat. Presuming that different kinds of weapons would have encountered one another in prehistoric armed clashes, we tested the swords not only against other swords but also against spearheads, spearshafts and replica wood, leather, and bronze shields. To allow for chronological consistency, all tests were carried out with weapons that would have existed contemporaneously (e.g. Ewart Park and Carp's Tongue swords). We chose not to mount the weapons on testing rigs as this would severely limit the range of actions we could replicate. Instead, we opted for rigorous field tests carried out by experienced sword fencers. Depending on their nature, and also for health and safety reasons, certain tests were carried out by two combatants, while others (e.g. full-force sword thrusts) were aimed at static shield targets. During person-onperson tests, the combatants wore full body protection comprising knee-length padded gambesons, metal gauntlets, and fencing masks. Overall, the CWTs involved 148 individual tests unfolding over 6 days. They were carried out at two open-air facilities 
in the North-East of England: Bede's World Museum (now Jarrow Hall) and the Durham University Botanic Garden.

The guiding principle in our CWT design was to break down 'real-life' combat sequences into their elemental components (e.g. a single strike or parry). This strategy ensured full control of wear formation processes as well as test consistency and repeatability. Working strike by strike and parry by parry, each action was individually filmed and photographed, and all marks thus generated were recorded photographically, with the location and shape of each mark being also noted and labelled. This allowed us to build direct links between specific combat moves and specific marks. Repeats of every experiment were built into the protocol so that we could investigate the reliability of our results. The CWT experimental protocol is described in Table 2.

All CWTs comprised static, kinetic, and dynamic sword parries. Our dynamic parries most closely mirrored live combat situations, in which both fighters would place force and speed behind the weapons, as one would in a real fight. Static parries, on the other hand, involved holding the defensive weapon still to receive the attacking strike, while during kinetic parries, the defender met the attack with a controlled movement towards the incoming weapon (Fig. 3). The force and velocity of the strikes were controlled empirically. Consistency between similar tests was ensured by having the same combatants hold the attacking and defending swords. Separating out static, kinetic, and dynamic parries allowed us to examine the relationship between different

Table 2 Controlled weapon tests: experimental protocol

Strikes

Leg strike The attacker swings the weapon with its tip facing downwards in a low-angled arc to strike the other weapon near the defender's legs, in the region of the knee area. The attack is parried with the defending sword pointing downwards at an angle.

Hip strike The attacker swings the weapon horizontally in an arc to strike the defender's weapon near the hip. The defending sword is held almost vertically pointing upwards in front of the hip. To counter the height of the blow the defender has to crouch slightly.

Shoulder strike The attacker swings the weapon in a diagonal arc from above to strike the defender's weapon near the shoulder or neck. The defender holds the weapon diagonally in front of the body, slightly raised towards the shoulder, with the tip pointing upwards towards the shoulder opposite the sword hand, to cover the upper body.

Head strike An overhead strike, coming straight down onto the defender's weapon in the head area. The defending sword is held horizontally above the defender's head.

Parries

Static edge parry The defending weapon is held in place to block the attacker's strike with the cutting edge.

Static flat parry The defending weapon is held in place to block the attacker's strike with the flat of the blade.

Kinetic edge The defending weapon is moving away from the defender's body, forcefully meeting the parry incoming strike with the cutting edge.

Kinetic flat parry

Dynamic edge parry

The defending weapon is moving away from the defender's body, forcefully meeting the incoming strike with the flat of the blade.

A kinetic parry carried out with so much force and momentum that it catches the attacking blade on the cutting edge and knocks it off its course. This parry may be best described as a weapon attack met by another weapon attack.

Dynamic flat As per above but the parry is executed with the flat of the blade.

parry 


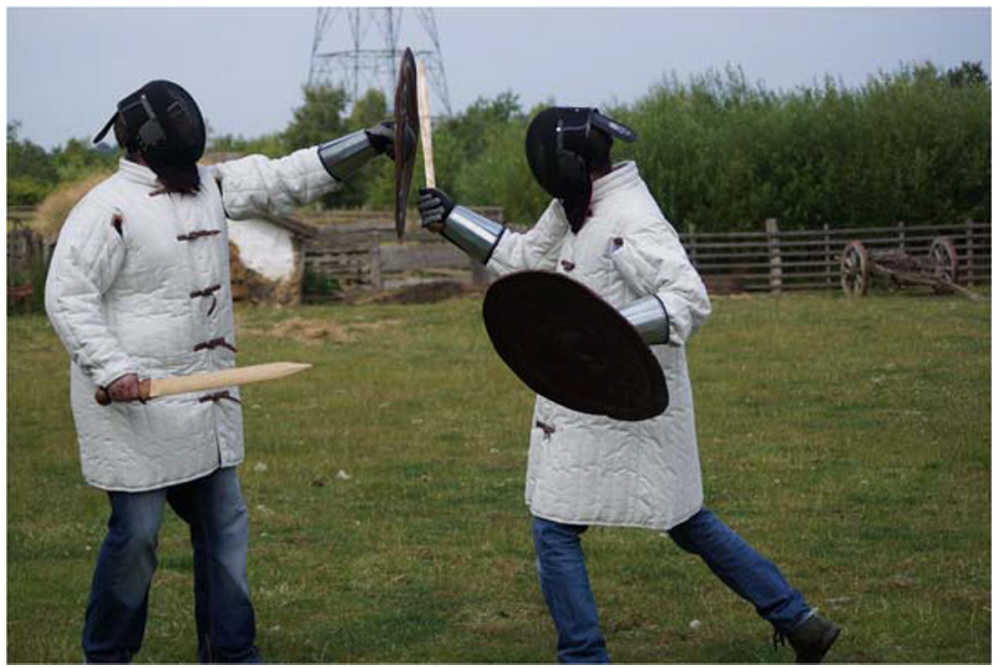

Fig. 3 Controlled weapon tests practice

marks and the conditions in which they were generated and to test the conclusions arrived at by other researchers in a non-laboratory environment. Moreover, certain tests (e.g. full-force blade-on-blade strikes) gave us insights into the ritual destruction of swords and how to differentiate combat marks from 'sword-killing' marks (Knight 2019).

This approach to sword testing has offered several advantages over either machinerun experiments or experiential fighting tests. Firstly, it has allowed us to connect specific combat actions with specific wear marks, generating a comprehensive reference collection that could be used for the wear analysis of archaeological swords. Secondly, it has given us insights into which part of the blade is affected the most during sword fighting and enabled us to discriminate between attack and defence marks. Thirdly, it has allowed us to move beyond some of the sword-centric work carried out in the past and let us consider how different weapons can be used in combination with one other (e.g. in a melee). Finally, it has provided an opportunity to investigate the grey area that exists between marks originating from use and those derived from acts of deliberate destruction (Crellin et al. 2018: 296).

However, the CWTs have also had several disadvantages. First and foremost, they provided poor proxies for the sophistication of a real sword fight, whose aim arguably is to hit the opponent in a vulnerable part of their body, not leave a mark on their weapons. Due to their nature and goals, our tests largely failed to capture the wear patterns that may arise from weapons hitting human bodies and armour (although the latter was partly achieved in our shield tests). As such, some of the marks created during our tests are best interpreted as instances of 'failed combat', in which unplanned strikes or parries are carried out and weapons clash against the will of the combatants, while other marks may be good proxies for the ritual decommissioning of swords prior to deposition (Knight 2019). Additional weaknesses of the CWTs encompass the following: limited control of strike force, velocity, and other variables affecting wear formation compared to laboratory experiments; the need to scale down the 
experimental protocol due to higher-than-expected rates of sword damage; unexpected variability arising from the use of several sword types featuring varying blade lengths, points of balance, weights, and geometries; and the vagaries of in-field recording, with all the problems one might expect to be caused by an open environment; and the lack of a fully equipped microscope laboratory (Crellin et al. 2018: 296-9). In order to offset these problems, we designed a series of experiential (or 'actualistic') weapon tests based on radically different principles and experimental protocols.

\section{Actualistic Weapon Tests}

Like the controlled tests discussed above, the actualistic weapon tests (AWTs) aimed to recreate prehistoric one-on-one sword fighting. However, they were not informed by the need to generate combat marks for wear analysis, but intended to test the capabilities of Bronze Age swords and combatants as an integrated functional unit, as would happen in real-life fencing. Creating marks on the weapons was simply a useful byproduct of the experiment, not its ultimate goal. As in the approaches advocated by Molloy (2007, 2008) and Gentile and van Gijn (2019), our AWTs fell between what Mathieu (2002) labelled 'functional replication' and 'phenomenological studies'. The term 'actualistic', introduced by Molloy (2008) and Outram (2008), describes an experimental setup that 'investigates activities that might have happened in the past using methods and materials that would actually have been available' (Outram 2008: 2; original text) through scenarios that are designed to be as close to real life as possible.

In such an approach, the functional controls that validate the accuracy of the analogy between ancient and experimental fighting are the morphology and mechanical properties of the weapon plus the biomechanical properties of the human body (Molloy 2008: 118). Weapon and body are understood here as a single biomechanical unit that is controlled by internalised cultural norms, instinctual responses rooted in neurological processes, and embodied practice (Malafouris 2008; Yun 2009). Here lies a crucial difference between the CWTs and AWTs: in the former, the human body operated the weapon but did not provide any knowledge-based inputs beside experienced handling and fine motor skills. The AWTs, on the other hand, were informed by bodily grounded knowledge about how to use a sword, which had been attuned through many years' learning and training. An important implication of this approach to the AWTs is that the tests had to be anchored to a predetermined body of knowledge acting as a methodological 'scaffold'. As with other experiential weapon tests, we selected a historic fencing manual: the 1452 Commentary by Andre Lignitzer on Sword and Buckler from folios 80r-80v, Codex 44.A.8, by Peter von Danzig (see Farrell 2012 for an English translation). Lignitzer's Commentary was interpreted through both academic scholarship and contemporary practice of Historic European Martial Arts (HEMA). HEMA is a growing international movement that strives to understand, practise, and popularise (mostly) late medieval and Renaissance combat treatises through scholarship and knowledgeable re-enactment (Anglo 2000; Clements 1997, 1998; Forgeng 2003; Talhoffer 2000; Wagner and Hand 2003).

We chose this treatise for several reasons. Firstly, the weapons described in it-short swords and bucklers (small round shields) - are typologically similar to the swords and shield replicas used in our tests, although the materials are different. Secondly, while the Commentary does not contain any images, it provides detailed descriptions of the 
combat actions, unlike many other sources from the time, which mainly rely on depictions. Thirdly, the Commentary has long been studied by various scholars, who have proposed broadly similar interpretations for the combat actions described therein (e.g. Warzecha 2017; Griswold 2016; Winslow and Winslow 2011). This gave us confidence that our tests would be grounded in accepted specialist knowledge. Working with distinguished HEMA specialists Robert Brooks and Andrew Milburn (Hotspur

Table 3 Actualistic weapon tests: experimental protocol. English transcriptions of plays after Farrell (2012)

Plays

Play 1

Play 2

Play 3

Play 4

Play 5

Strikes

Oberhaw (over strike) The attacker delivers a downwards strike to the opponent's head, shoulder, arm or hip from a raised position, e.g. from over the attacker's own shoulder or head.

Underhaw (under strike)

Mittelhaw (middle strike)

Wechelhaw (changing strike)

Twer (cross strike)

Schaitlär (skull strike) The attacker executes a short, quick blow directly at the opponent's skull. This can be directed horizontally to strike the forehead or vertically to strike the crown of the head.

Sturtzhaw (plunging strike)

Versetzen

(displacement)

The first play with the buckler from the Oberhaw (over strike / strike from above). Mark when you drive the Oberhaw to the man: with the pommel go inwards, your sword close to the buckler and your thumb, and thrust in from beneath to his face. Wind against his sword and then go with a snap over and around.

From the Underhaw (under strike / strike from below), when he strikes from above. Wind against him to your left side, [with his sword] against your shield. Thus you stand in two shields. So wind to the right side opening and strike in at the mouth. See if he deals with this by raising his shield, and if so then take the left leg. This works on both sides.

From the buckler, from the Wechelhaw (changing strike), sweep from the left side. From your buckler sweep clearly above with your sword then cut into his head from the left side; wind [to the] opening and thrust into his mouth. If he lifts with the shield and with the sword and defends against this then cut with the long edge in at his right leg. This works on both sides.

From the Mittelhaw (middle strike) make the Twer (cross strike) to both sides and the Schaitlär (skull strike) with the long edge, then make a thrust in underneath.

From the Sturzthaw (plunging strike) make as if to go to [his] left side over his shield with a thrust then with the point change under and thrust swiftly inside his shield. Wind immediately to your left side and if he defends against this then take his right leg with your long edge.

The opposite of an Oberhaw. This time, the attacker strikes in an upward motion from a low position, e.g. from the attacker's own hip.

Unlike the Oberhaw (striking from above) and the Underhaw (striking upwards), the Mittelhaw is a left-to-right horizontal or slightly diagonal side cut.

When the attacker's initial strike is parried/deflected, they suddenly change into a different cut directed against another unprotected area of the target.

The attacker strikes twice horizontally, once from each side. A Twer can also be used to displace downwards blows coming from above; this is then immediately followed by a counter-attack on the other side (Wechelhaw)

The attacker strikes at the opponent from a high position but with the back cutting edge; this results in the tip of the sword pointing at the target's face.

Displacing and controlling of the opponent's weapon by deliberately searching contact between the two blades. Verstezen is often combined with twisting one's own weapon in order to set oneself up for the next attack while maintaining blade contact. 


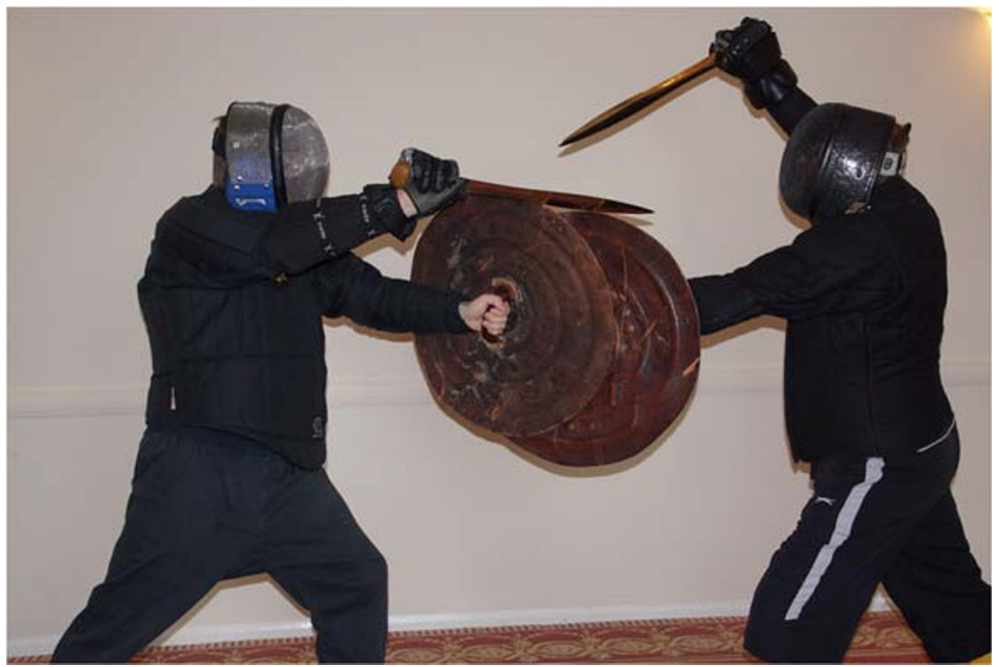

Fig. 4 Actualistic weapon tests: final stance of the fifth play

School of Defence), we replicated five combat sequences out of the six described in the Commentary (plays one to five, Table 3). The sixth play is designed to take the opponent's shield and does not involve any sword contact; as such, it was left out of the protocol (Fig. 4).

To overcome the complications of in-field recording experienced during the CWTs, we decided to hire an indoor location (St. Luke's Church hall, Newcastle upon Tyne), which provided us with a safe and sheltered space to conduct the AWTs. We were also able to set up an in situ microscopy laboratory in a side room of the church hall, where full identification and recording of marks took place immediately after each combat sequence. This offset the risk that later plays would cause earlier marks to be erased or damaged. The combatants fought with two brand new Ewart Park replica swords (exact copies of the replicas used during the CWTs) and the two Cloonbrin replica leather shields used in the previous experiments. They practised each play repeatedly with wooden training swords before carrying out the tests. Although plays 1 to 4 were only conducted once each, the individual actions are often repeated in the different plays (e.g. Versetzen appears in four of the five plays; see 'Bulge'). This ensured a better understanding of mark formation processes. The fifth play was conducted twice, as the first attempt created no marks on either sword and we wished to rule out that this was just a chance occurrence. During the live tests, the combatants wore personal protective equipment consisting of fencing masks, thick padded gambesons, and steel-clad gauntlets. Videos and photographs of the combat sequences were taken with a SONY Cybershot DSCH300B Bridge Camera and Olympus Stylus Touch, respectively. The AWT experimental protocol is described in Table 3 .

The AWTs featured several notable strengths complementing those of the CWTs. First, they were firmly grounded in fifteenth century swordsmanship, which is characterised by high degrees of sophistication and finesse (Gassmann et al. 2017: 119). This, we posited, would provide a compelling historical analogy for Late Bronze Age sword fighting, which, like its late medieval counterpart, stood at the cusp of a 
sword fighting tradition going back several hundred years. Secondly, the AWTs did not subject the weapons to the same mechanical stresses as the CWTs. This ensured excellent cutting edge preservation throughout the combat sequences, allowing us to complete all actions planned. Finally, we were able to microscopically record the combat marks on the swords immediately after each fighting sequence; thanks to the 'flying laboratory', we had set up next to the experimental hall.

As for the limitations of our AWTs, the most notable was the difficulty to identify exactly which mark was caused by which action during a combat sequence. The problem was partly offset by keeping the sequences short (typically 4 s) and using high-speed cameras and digital photography, supported by inputs from the combatants, to understand which action had caused which mark. Another notable disadvantage of the AWTs was their being tied to a specific historic fencing style. This presented a significant risk of circularity in test design, data generation, and data interpretation, whereby we would make certain preconceived assumptions about how Bronze Age swords would be used; we would test the swords based on these assumptions; and, with perhaps the odd exception, we would demonstrate our assumptions experimentally. This is one of the greatest risks of grounding prehistoric weapon testing in historic sources. We knowingly offset this risk not only by comparing and contrasting the marks generated by both actualistic and controlled tests but also by validating both through the wear analysis of archaeological swords.

\section{Metalwork Wear Analysis}

In order to identify and record archaeological combat-related wear traces, and to interpret them by reference to both CWTs and AWTs, we analysed 110 Middle and Late Bronze Age swords from British (70 specimens) and Italian (40 specimens) museum collections. The swords were selected on account of chronology, typology, and degree of overall surface preservation. Only complete swords with excellent visibility of wear marks were included in the study (Table 4).

The analysis was conducted by one of the authors $(\mathrm{RH})$ following the methodology described in Dolfini and Crellin (2016), adapting the analytical protocol laid out in Dolfini (2011) and Crellin (2018). No casts of the prehistoric swords were taken. The analysis was carried out on the original objects at museums, using a Huviz HSZ stereoscope equipped with a GX-Cam 9 camera and built-in cold light source. Additional lighting was provided by a portable gooseneck spotlight. In a few instances, it proved impractical to carry the bulky Huviz microscope to the museums. In these cases, the analysis was carried out with a GXM-DinoLite Pro AM-413T digital microscope. A sample of Bronze Age swords from the Great North Museum collections, Newcastle upon Tyne, was analysed with both microscopes to evaluate consistency in data collection and recording. It was found that all marks described below could be identified and classified correctly using either device, although the microphotographs taken with the DinoLite could be of inferior quality.

All swords were visually inspected, described, weighed, drawn, and photographed. Subsequently, they were microscopically examined at magnifications ranging from $\times 8$ to $\times 40$, and all macroscopic and microscopic wear marks were noted on the 1:1 drawings, recorded in a MS-Excel database, and digitally photographed. As no universally accepted terminology for metalwork wear traces has yet been established (Gentile 
Table 4 Bronze Age swords examined as part of the research, by museum

\begin{tabular}{|c|c|c|}
\hline Museum & Chronological phase & $\begin{array}{l}\text { Number of swords } \\
\text { analysed }\end{array}$ \\
\hline \multicolumn{3}{|l|}{ Britain } \\
\hline \multirow[t]{4}{*}{ British Museum } & Penard (c. 1275-1140 BC) & 1 \\
\hline & Wilburton (c. 1150-950 BC) & 2 \\
\hline & Ewart Park (c. 950-800 BC) & 11 \\
\hline & Llyn Fawr (c. 800-600 BC) & 6 \\
\hline \multirow[t]{4}{*}{ Museum of London } & Penard (c. 1275-1140 BC) & 4 \\
\hline & Wilburton (c. 1150-950 BC) & 8 \\
\hline & Ewart Park (c. 950-800 BC) & 10 \\
\hline & Llyn Fawr (c. 800-600 BC & 3 \\
\hline \multirow[t]{2}{*}{ Great North Museum: Hancock } & Ewart Park (c. 950-800 BC) & 6 \\
\hline & Llyn Fawr (c. 800-600 BC & 2 \\
\hline \multirow[t]{5}{*}{ Yorkshire Museum of Archaeology } & Penard (c. 1275-1140 BC) & 3 \\
\hline & Wilburton (c. 1150-950 BC) & 1 \\
\hline & Ewart Park (c. 950-800 BC) & 3 \\
\hline & Llyn Fawr (c. 800-600 BC) & 1 \\
\hline & Unknown & 1 \\
\hline Alnwick Castle Museum & Ewart Park (c. 950-800 BC) & 6 \\
\hline Preston Park Museum & Ewart Park (c. 950-800 BC) & 2 \\
\hline \multicolumn{3}{|l|}{ Italy } \\
\hline \multirow[t]{2}{*}{ Soprintendenza Archeologica per il Veneto } & $\begin{array}{l}\text { Middle Bronze Age (c. } \\
\quad 1650-1300 \mathrm{BC})\end{array}$ & 21 \\
\hline & $\begin{array}{l}\text { Recent Bronze Age (c. } \\
\quad 1300-1200 \mathrm{BC})\end{array}$ & 9 \\
\hline \multirow[t]{4}{*}{$\begin{array}{l}\text { Museo Nazionale Preistorico Etnografico } \\
\text { Luigi Pigorini }\end{array}$} & $\begin{array}{l}\text { Middle Bronze Age (c. } \\
\text { 1650-1300 BC) }\end{array}$ & 2 \\
\hline & $\begin{array}{l}\text { Recent Bronze Age (c. } \\
\quad 1300-1200 \mathrm{BC})\end{array}$ & 6 \\
\hline & $\begin{array}{l}\text { Final Bronze Age (c. 1200-900 } \\
\text { BC) }\end{array}$ & 1 \\
\hline & Early Iron Age (c. 900-725 BC) & 1 \\
\hline
\end{tabular}

and van Gijn 2019: 136), the use marks were classified using a nomenclature originally created for this research (see Section 3), drawing on the literature (Bridgford 2000; Horn 2013; Molloy 2011; O'Flaherty et al. 2011; Uckelmann 2012). To prevent misinterpretation and facilitate comparison with the literature, we described each mark type individually rather than grouping similar (or functionally related) traces under overarching labels. All primary MWA data including the MS-Excel database and micrographs can be accessed as supplementary online material. 
Table 5 Use-related marks identified on 110 archaeological Bronze Age swords from Britain and Italy. Of these, 14 were recreated during the combat experiments. The table details whether the marks were created during the controlled or actualistic weapon tests and if they were caused by an attacking or a defending motion (limited to the controlled tests)

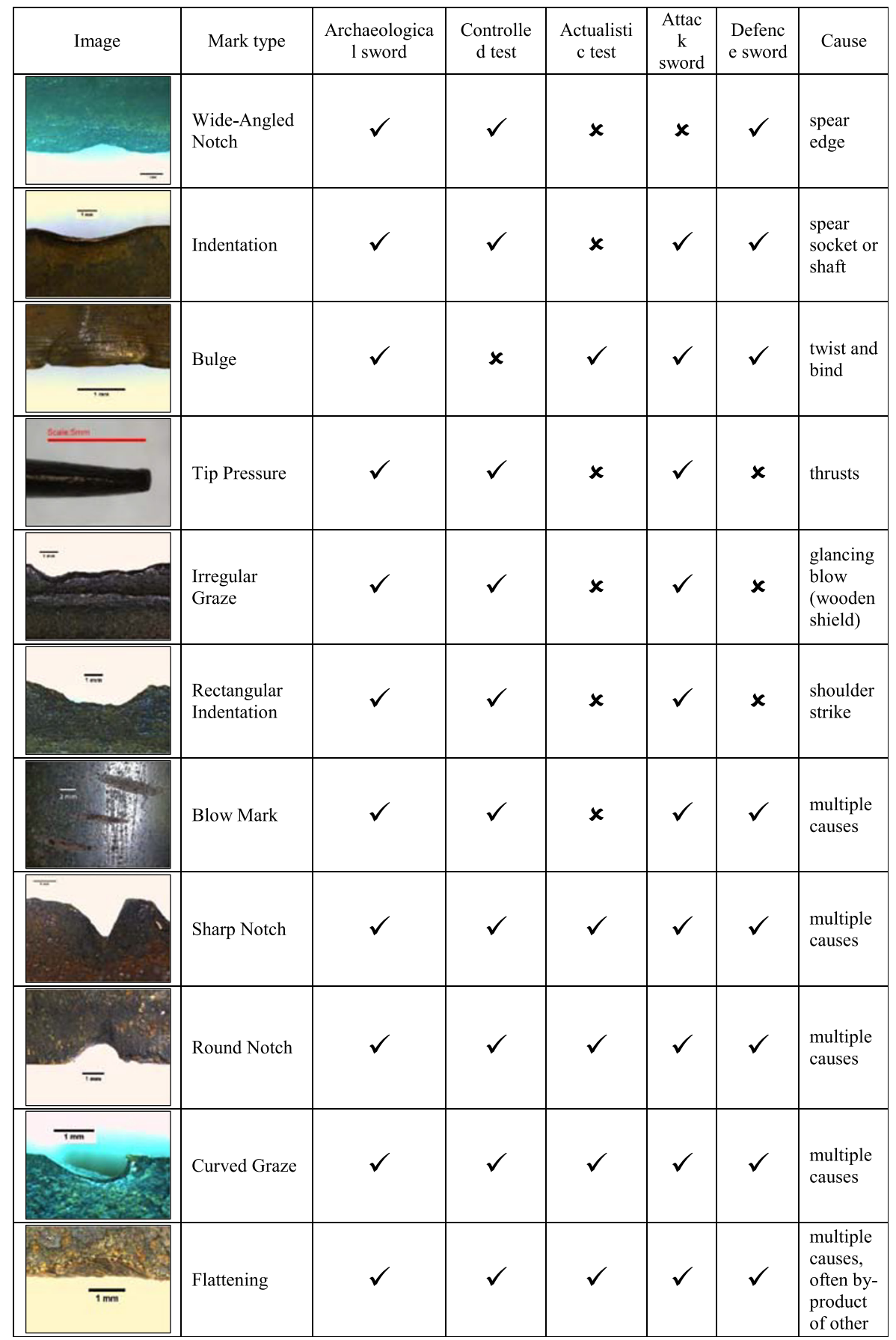




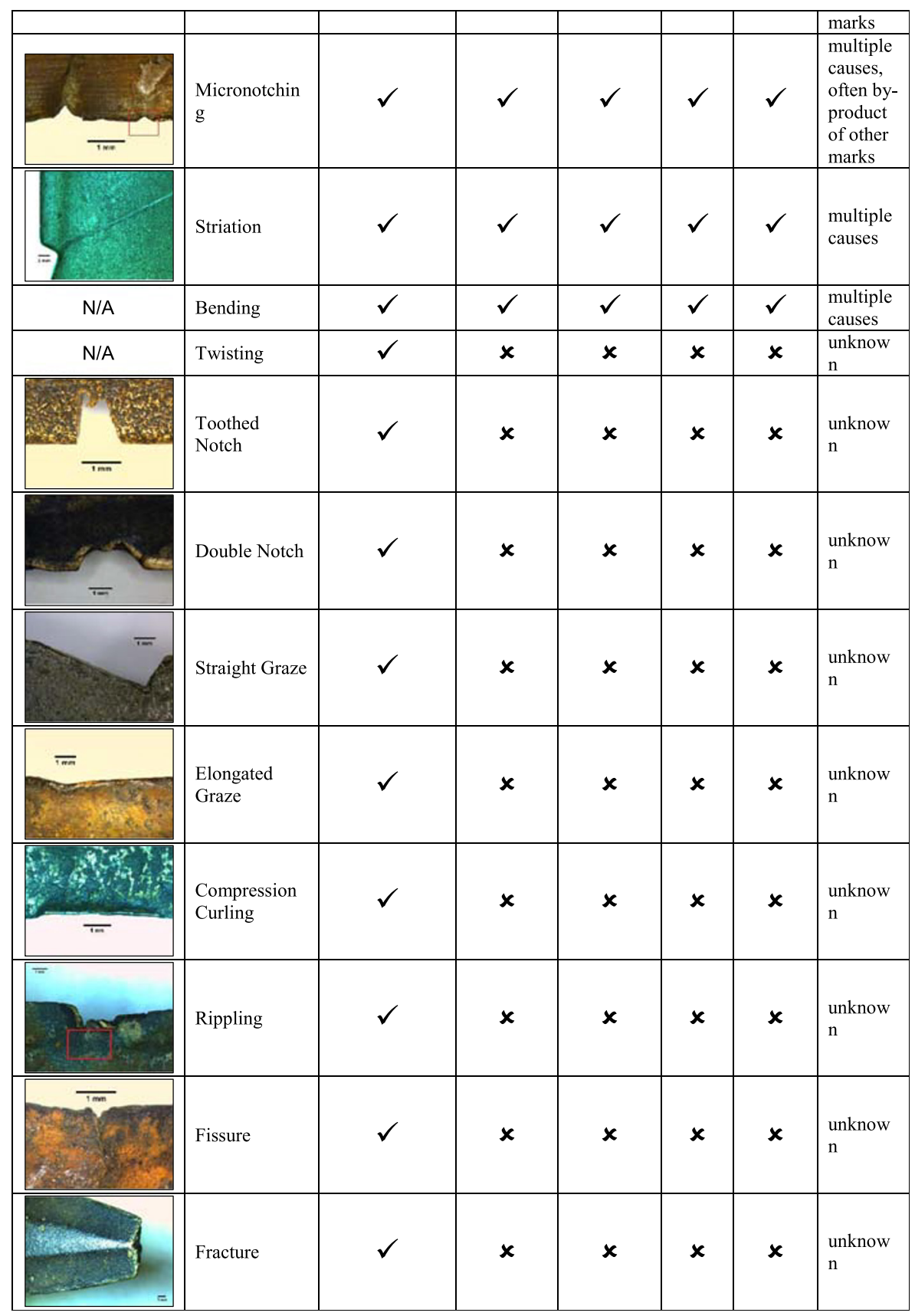

\section{Data Analysis}

The wear analysis of the archaeological swords has revealed 23 different types of userelated marks (Table 5), all of which were covered by a thin layer of oxidisation 
products, or patina, as is mostly the case with ancient marks (Roberts and Ottaway 2003: 120). Manufacturing and post-depositional marks (disturbing the patina) were noted during the analysis (included in supplementary material) but are not discussed in this paper. Fourteen of the archaeological use marks were recreated during the weapon experiments, either controlled or actualistic (or both: Table 5). Some of these marks can securely be linked to specific combat actions (e.g. bulges and tip pressure) or weapon encounters such as sword vs spear (e.g. wide-angled notches and indentations). Others, however, were caused by a number of different actions (e.g. notches, grazes, flattening, and bending). Blow marks, rectangular indentations, and irregular grazes were each only recreated once, and it is therefore doubtful if they can solely be interpreted by reference to the action described.

Limited to the CWTs, it was often possible to link use marks to the attacking or defending motions executed with the replica swords, as the two motions were clearly differentiated. Such distinction was lost in the AWTs as, by their very nature, these tests did not rely on a clear-cut separation between attack and defence, but on fluid combat sequences in which a defensive action could quickly be turned into a counterattack, and vice versa (see 4.2). Of the 14 marks recreated during the combat tests, six were deemed diagnostic, i.e. were created by a single, specific combat action. As such, they provide prime direct evidence of Bronze Age swordsmanship. To these, we can add a distinctive pattern of blade damage caused by a blocking action on the defending sword, which finds exact parallels in the archaeological record. These damage patterns and their causes are discussed in 'Diagnostic Combat Marks'.

\section{Diagnostic Combat Marks}

\section{Wide-Angled Notch}

Wide-angled notches (Fig. 5) have a wide, shallow angular profile. They were exclusively created when the sword's cutting edge impacted on the cutting edge of a spearhead. Due to the difficulty of connecting the sword with the spearhead, these marks were only created twice during the CWTs (Fig. 6). This is reflected in the archaeological record, which has yielded only 64 wide-angled notches on 36 swords from Britain and Italy (Fig. 5b).

\section{Indentation}

Indentations are wide and shallow and have a distinctively rounded profile (Fig. 7). They are caused by the sword's cutting edge connecting with the round socket or wooden shaft of a spear (Fig. 8). During the experiments, it proved easy to achieve good contact between sword and spear shaft due to the length of the latter. The archaeological record (Fig. 7b) reflects this well, for the wear analysis has revealed 693 indentations on 91 swords.

\section{Bulge}

Bulges are defined as material displacements of the cutting edge, whereby the metal is deformed in such a way that it bulges out to the side (Fig. 9). They were solely created 
during the AWTs as a result of a Versetzen (displacement). Versetzen is a fencing technique that seeks deliberate contact with the opponent's blade in order to bind and control it (The Association for Renaissance Martial Arts 2019; Fig. 10). As the blades are twisted during the bind and the cutting edges come into contact, millimetre-sized bulges are left on the blades. Bulges occur in roughly equal measure on both the controlling and the controlled weapon. Interestingly, the HEMA swordfighters observed that Versetzen was exceptionally well suited to bronze swords as the material properties of this metal caused the two blades to 'stick together' in ways not experienced with steel swords. This suggests that similar sword binding techniques may have been practised by Bronze Age fighters. The inference is supported by the wear analysis of archaeological swords, which shows 111 bulges on 39 specimens (Fig. 9b).

\section{Tip Pressure}

Tip pressure is a characteristic flattening of the sword point created as the sword is thrust against a hard surface (Fig. 11). In the CWTs, tip pressures were created by sword thrusts against both the wooden and the bronze shield (Fig. 12). In contrast, the sword point was not flattened or otherwise damaged when thrust against the leather shield, which proved relatively easy to pierce. Tip pressures were observed on 35 archaeological specimens from the sample (Fig. 11b).

\section{Irregular Graze}

An irregular graze is a triangular mark in the cutting edge with one flank noticeably longer than the other (Fig. 13). The long flank is jagged and does not follow a distinctive profile. During the CWT, an irregular graze was only created on one occasion as a result of a sword slash to the wooden shield (Fig. 14). Irregular grazes are common in the archaeological record, with 182 recorded on 63 Bronze Age specimens (Fig. 13b).

\section{Rectangular Indentation}

Rectangular indentations are similar to indentations (see 'Indentation'), but instead of a rounded impact profile, they have angular outlines (Fig. 15). In the CWT, a rectangular indentation was created in the attacking sword as the result of a shoulder strike defended with a static edge parry (Fig. 16). Rectangular indentations are a rare occurrence on archaeological swords, with only 25 recorded examples on 17 specimens (Fig. 15b).

In addition to these marks, a distinctive damage pattern was identified on four archaeological swords (IDs 11, 59, 71, and 105; Figs. 18 and 19). This consists of oblique striations on the flat of a bent blade, with bending in the range of $10^{\circ}$ from the original longitudinal axis. We hypothesised that this recurring damage pattern could have been caused by flat parrying - a fencing technique that uses the flat of the blade to block an incoming attack, typically by another sword, in order to preserve the defending sword's cutting edge. The method was routinely practised in medieval and post-medieval fencing as it suited the tensile strength, toughness, and ductility of steel blades (Clements 2002). Despite notable differences in the material properties of bronze 
and steel, it has been suggested that flat parries might have been carried out with prehistoric swords, too (Mödlinger 2011a: 164). We put this suggestion to the test.

The controlled test consisted of a sword strike directed to the leg, which was blocked by a dynamic flat parry. We used the Wilburton type sword replica for the attack and the Vollgriffschwert (which has a wide leaf-shaped blade and narrow midrib) for the parry (Fig. 20). The forceful impact of the attacking blade caused the defending blade to bend by about $10^{\circ}$; it also left a distinctive pattern of striations on the blade flat. This is the same combination of marks and blade bending found in the archaeological swords (Figs. 17, 18, and 19). As the damage was so severe that it disabled the defending replica sword, one presumes that Bronze Age fencers would have avoided flat parries as much as possible. This begs the question as to what may have caused the damage observed on the archaeological swords: was it a planned combat action gone wrong? Was it a last-resort hard block, perhaps to save one's life? Or was it intentional ritual damage carried out before the sword was committed to the ground or water? While the latter cannot be excluded, it is noteworthy that Gentile and van Gijn (2019: 137-8) report sword bending during their experiential combat tests, caused by either hard blocks (similar to our flat parries; Fig. 20) or deflections. Although they do not elaborate on the observation, the Gündlingen-type swords used for their tests ostensibly sustained less damage than our Vollgriffschwert, and their damage pattern seems also different from ours. These discrepancies can probably be ascribed to the dissimilar testing protocols and degree of force applied in the two experiments, with alloy composition, blade geometry, hardness, and microstructure also being possible factors.

\section{Patterning and Clustering of Wear Marks}

As the flat parry case study suggests, the association of wear marks into distinctive patterns, as well as their clustering in certain sections of the blade, can be more informative about prehistoric fighting styles than individual marks. Clusters are defined here as groups of two or more marks, of any type, lying next to one other, while a pattern is the spread (or the extent) of one mark type along the entire sword (Fig. 21). While no clustering was created either in the CWTs or the AWTs, the wear analysis has revealed several instances of mark clusters on both British and Italian archaeological swords. Overall, 325 clusters have been identified on the 110 swords examined for this study, comprising 742 combat-related marks in total, which resulted from repeated impacts on the same section of the blade (Fig. 22). Most clusters consist of two marks (254 clusters), followed by 53 clusters of three marks, 15 clusters of four marks and three clusters of five marks (Table 6). The most common marks represented within the clusters are indentations $(31.8 \%, 236$ marks), round notches $(19.0 \%, 141$ marks) and sharp notches $(9.4 \%, 70$ marks).

Although mark clustering could potentially be a chance occurrence, its frequency suggests that this is not the case. Clustering is more likely to be the result of carrying out the same combat action or fighting sequence numerous times, using the same part of the blade. This suggests that the fighter must have achieved excellent control of the weapon through sustained training. It is unfortunately difficult, in all but a handful of cases, to determine the exact nature of the action or sequence that generated the cluster as most marks are unspecific, i.e. they may be caused by several strikes or other uses of the weapon (Table 5). Clusters of multiple (primary) marks must be distinguished from 
micronotching. Like clusters, micronotches are found in close proximity to other marks. However, fighting experiments suggests that they are to be interpreted as secondary marks caused by the attacking sword rebounding on the defending weapon, as the kinetic energy of the attack is not entirely dissipated by the first impact (Gentile and van Gijn 2019, 135; Hermann et al. 2020). Though easy to identify due to their tiny size and their location next to a larger primary mark, micronotches rarely survive in the archaeological record due to surface corrosion or possible repair in prehistory. In this study, we have been able to identify only 35 micronotches out of 2367 combat-related marks (Fig. 23).

Unlike clusters, which group together any mark types, a pattern is defined as the spread of a single mark type along the entire blade. The most common are indentations, bulges, notches, and grazes. While bulges and indentations are caused by specific, knowable combat actions (see 'Wide-Angled Notch' and 'Indentation'), notches and grazes are more difficult to interpret, as they may have multiple causes (Table 5). As with clusters, the extent of patterns of combat marks can suggest a repeated deliberate use of that particular portion of the blade, which implies a certain degree of motor control due to weapon training.

Interestingly, if one breaks down mark patterns by sword chronology, one can see distinctive developments in their occurrence and concentration over time. To visualise where the main patterns are located along the cutting edges and how patterning changed over time, the dataset must first be normalised. To compare swords of different lengths, the formula $y=(d / D) \times 100(d=$ distance of mark from the tip, $D=$ total length of sword) is used to express each mark's distance from the blade tip as a percentage of the entire length of each sword. The decision to calculate the distance as a percentage of the sword length, rather than of the blade, was due to the difficulty of establishing the exact limits of each sword blade. Unlike medieval swords, in which the length of the blade can be expressed as the distance from tip to crossguard, Bronze Age swords have no crossguards marking the end of the blade. Other indicators such as the length of the bevel lines from tip to ricassi (i.e. the unsharpened portions of the blade just above the shoulders) are not uniformly present in the sword sample either. In fact, many Bronze Age swords lack bevel lines, ricassi or shoulders altogether, while in others, the bevels are of different lengths, the ricassi are askew, and the midrib starts from the hilt. The whole length of the sword was therefore thought to be the only reliable variable to consider for cross-comparison. Deviations due to fractured tips or grip tongues are negligible as broken or incomplete swords were excluded from the sample (see 'Metalwork Wear Analysis'). The swords were analysed in chronological order: for Britain, by metalworking stage (i.e. Penard, Wilburton, Ewart Park and Llyn Fawr; Needham 1996, 122; Needham et al. 2015, 82; Roberts et al. 2013, 19), and, for Italy, by chronological phase (i.e. Middle, Recent and Final Bronze Age, followed by Early Iron Age; Nicolis 2013, 694; Fig. 24). For each mark type, the outliers were removed and the interquartile range (IQR) was calculated to illustrate the spread of marks along the cutting edges (Fig. 25).

In Britain, a clear trend towards mark concentration can be observed from the Middle to the Late Bronze Age, until it suddenly reverses with the emergence of the Iron Age, in the Llyn Fawr Phase. During the Penard Phase, mark patterns are predominantly evenly spread along about $70 \%$ of the sword length. This changes in the Wilburton Phase, in which marks are overall grouped within $50 \%$ of the sword. In 
this phase, notches and bulges are clustered within only $26 \%$ of the sword length, normally just above the leaf-swelling of the blade. The trend continues in the Ewart Park Phase, in which marks are clustered within approximately $45 \%$ of the blade, but reverses in the Llyn Fawr Phase, when marks are once again spread along the entire length of the cutting edge. Similar trends are observed on Italian swords. During the Middle Bronze Age, mark patterns are located roughly within 50\% of the blade, while in the Recent Bronze Age, they are tightly clustered within only $35 \%$ of the sword length. No trends can be observed for the Final Bronze Age or Early Iron Age as the dataset solely includes one specimen each for these phases. Notably, bulges are absent from the Middle Bronze Age Italian record but become common in the Recent Bronze Age. The significance of this finding (and of the other data presented above) is discussed in the next section.

\section{Discussion}

This section considers the social realities of Bronze Age sword fighting as inferred from the experiments and analytical data discussed above. It explores in-depth several problems in Bronze Age swordsmanship including how to hold a sword and to fight with it, target areas, and the evolution of fencing styles from the Middle to the Late Bronze Age.

\section{Holding a Bronze Age Sword: Grip, Handedness, and Edge Dominance}

Before discussing how Bronze Age swords could have been used, we should consider how they were held. The shapes, weights, points of balance, and geometries of these weapons, especially their short hilts, lack of crossguards, and frequent ricassi, enable fighters to grip them in different ways (see Molloy 2007, 2010 for discussion). Three ways of holding swords were experimented with during our controlled and actualistic tests: 'hammer grip', in which the four fingers of the hand form a fist around the weapon and the blade is held perpendicular to the forearm (Molloy 2010, footnote 121); 'sabre grip', in which the fist is stretched to an angle so that the blade is aligned with the forearm (Molloy 2010, footnote 122); and 'thumb grip', in which the sword is twisted by $90^{\circ}$ so that the cutting edges lie sideways and the thumb is pressed on the flat of the blade (Gener 2018, 167; Fig. 26).

Hammer grips are suitable for most Bronze Age swords. Kristiansen (2002: 321) suggests that the short hilts and pommels typically found on these weapons help 'lock' the fighter's hand into place, providing excellent control of the weapon. Our experiments support his suggestion. Hammer grips allow rapid changes of direction and trajectories of attack, as well as percussive strikes using a combination of force and finesse (Molloy 2010: 419). Sabre grips, on the other hand, enable users to align the cutting edge to the natural trajectory of the strike, as well as curl their index finger around the shoulder - an opportunity that was not lost to early fencers considering the frequency of ricassi on Bronze Age swords. Holding the sword in such a way limits the user's ability to make percussive strikes but allows fine control of the weapon in cutting attacks (Molloy 2010: 418). Finally, thumb grips permit excellent command over the weapon, including the ability to make quick changes of direction and execute thrusts as 


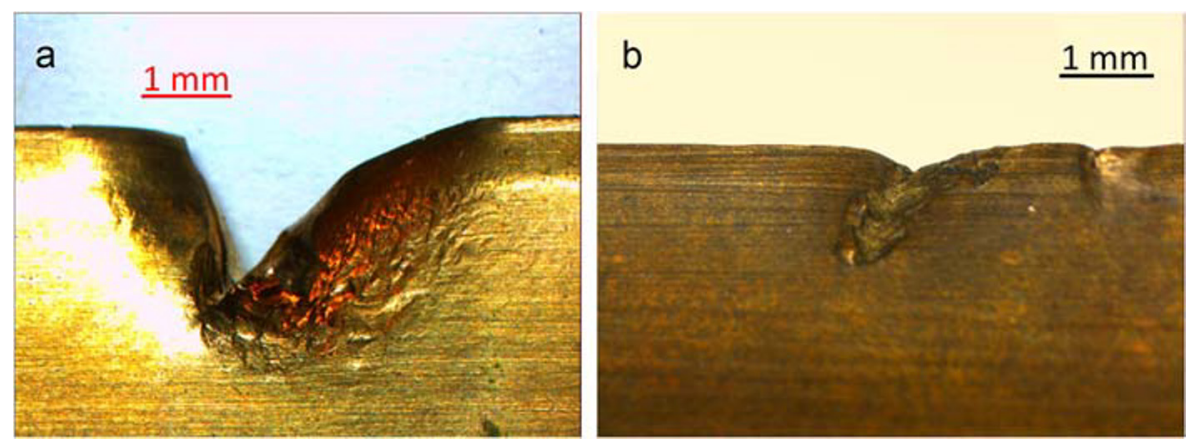

Fig. 5 a Replica wide-angled notch from test 31e.4. b Archaeological wide-angled notch, mark ID 151

well as backhand strikes (i.e. strikes executed with the back cutting edge). Our experiments suggest that there is no 'correct' way of holding a sword, although certain swords may favour certain grips over others due to their length, balance, and other features (e.g. ricassi). In most cases, however, all grips can be used interchangeably during a sword fight to deliver different kinds of attack, depending on the fencer's preferred combat style and other circumstances. Bronze Age swords can afford further grips including inverted grips (enabling downward thrusts) and pommel grips (for increased reach; see Clements 1998: 77-81, for discussion; Fig. 27). These, however, were not experimented with during the project.

To some extent, how a sword is held and used depends on the bearer's handedness. The functional implications of handedness, including its influence on wear formation in prehistoric tools, have long been explored in archaeology and human evolution studies (Spenneman 1987; Steele and Uomini 2005; Uomini 2009). Generally, these studies have shown that most tool users would conform to the natural $85 / 15$ approximate ratio of right-handed vs left-handed individuals found in human populations (Steele and Uomini 2005: 217). Unless it was discouraged by cultural norms or weapon training

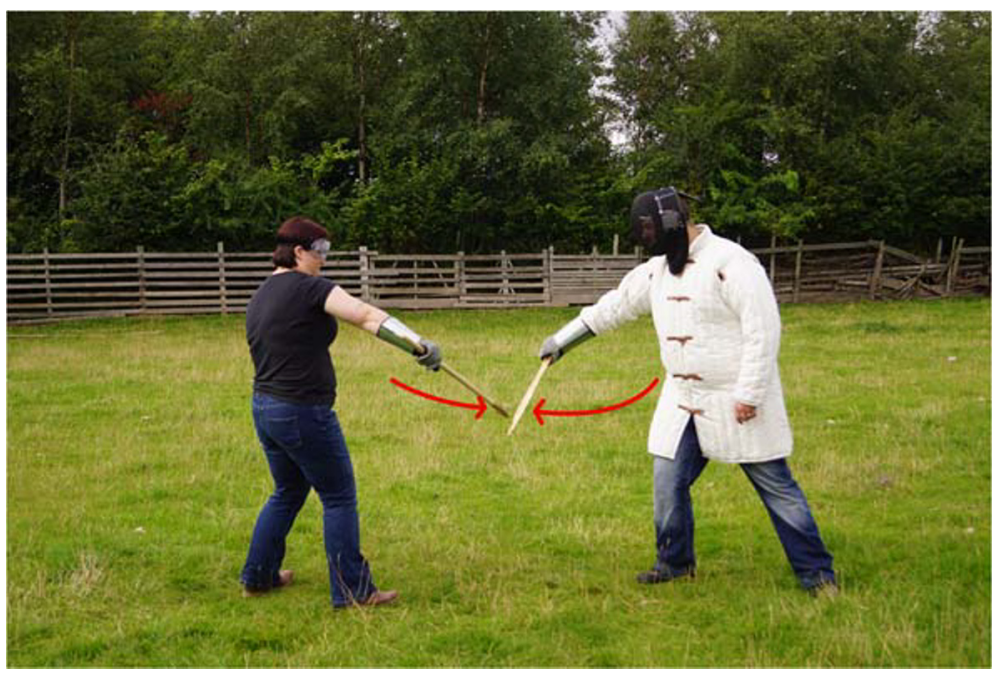

Fig. 6 Controlled weapon test 31e.4: long spearhead (on a short shaft) vs dynamic sword edge parry. This caused the formation of a wide-angled notch on the sword's cutting edge 


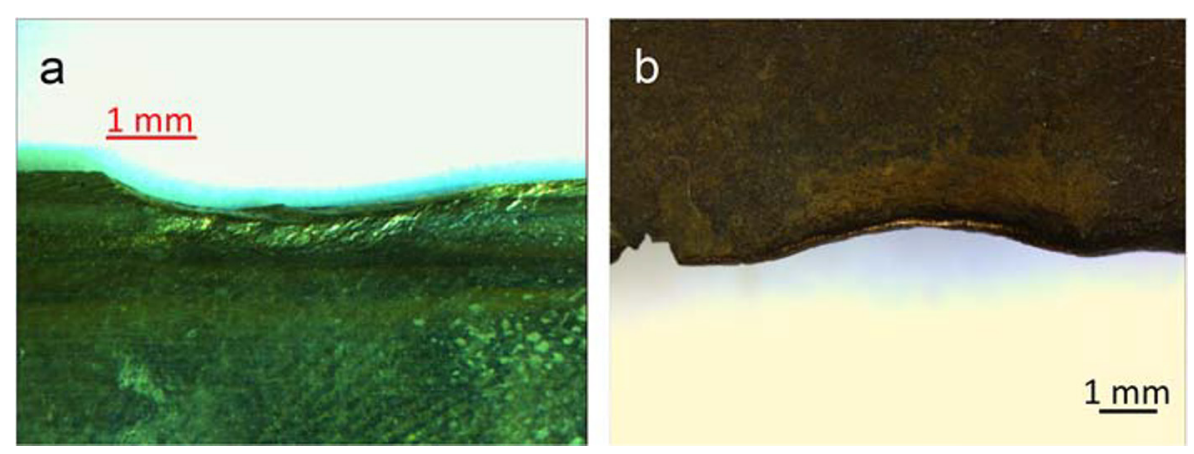

Fig. 7 a Replica indentation from test 27 g. b Archaeological indentation, mark ID 106

deterring left-handedness (Gentile et al. 2018), we would expect early sword bearers to conform to this ratio, as they would hold the weapon with their hand of choice. In our actualistic tests, both HEMA fighters held the sword with their right hands and had the same cutting edge always pointing forwards. They both remarked that it 'felt natural' to maintain edge dominance over time, even when the weapon is perfectly symmetrical. This being the case, a greater number of marks formed on the forward edge than on the back edge of the replica weapons, with those on the back edge mostly ascribed to backhand strikes. This is consistent with the wear analysis of archaeological swords, which has demonstrated unambiguous edge dominance on 31 out of 110 specimens in the sample. It is presently unclear why two/thirds of the weapons do not show clear edge dominance. Reasons may range from multiple ownership of the sword to 'edge flipping' as wear built up on the forward cutting edge, making it increasingly blunted and ineffective.

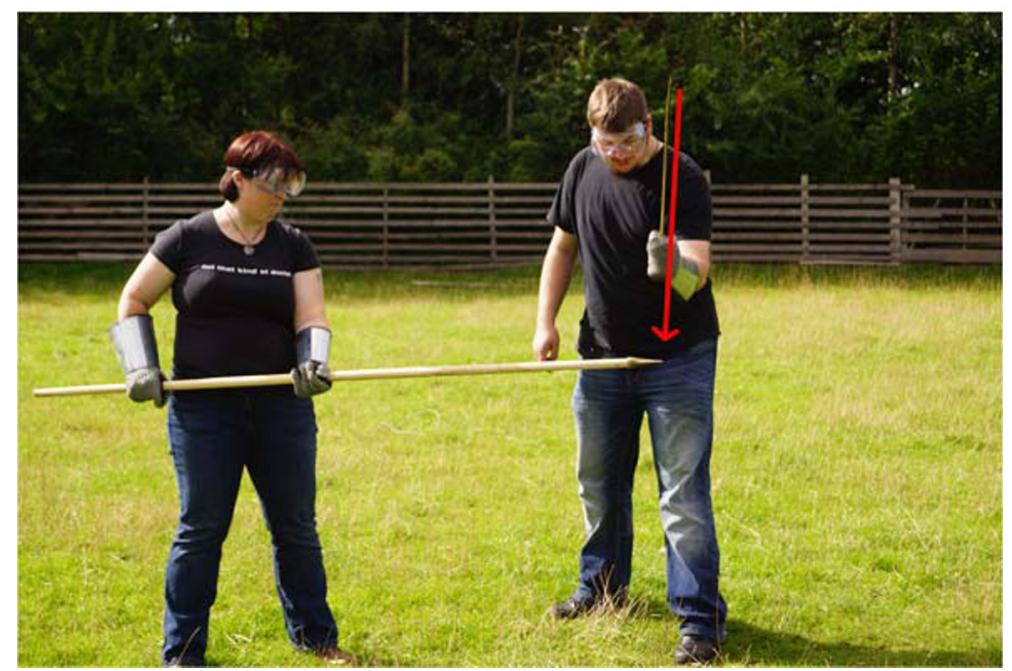

Fig. 8 Controlled weapon test $27 \mathrm{~g}$ : sword vs kinetic strike on the socket of the spear head. This caused a distinctive indentation in the cutting edge of the sword 

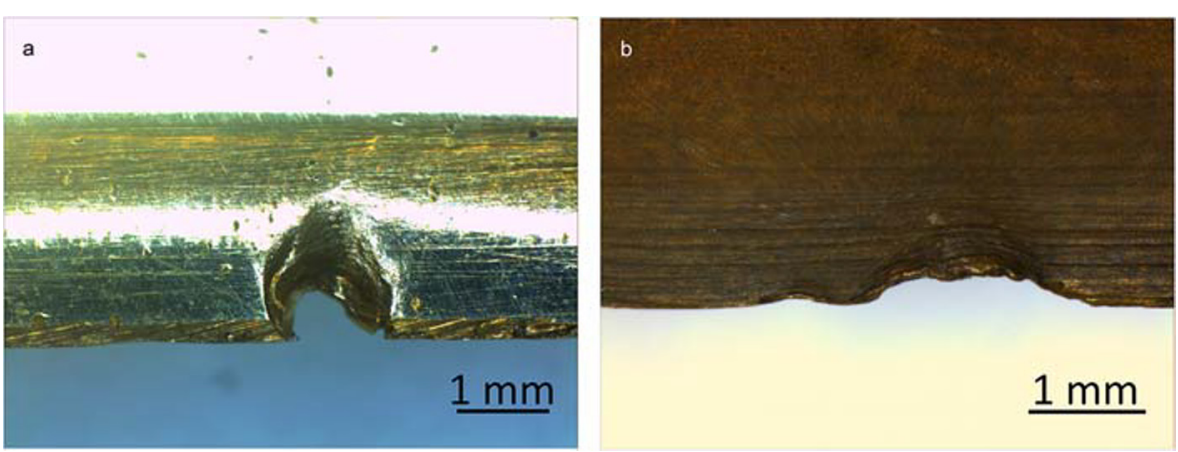

Fig. 9 a Replica bulge from test 304b. b Archaeological bulge, mark ID 127

\section{Prehistoric Sword Fighting: Attacks, Defences, and Blade-on-Blade Contact}

In popular culture, it is an enduring trope that sword fighting can be divided into attacking strikes and defending blocks, which would be exchanged with flamboyant swinging blows from some distance. This view, however, is far removed from the reality of historic sword fencing, which is often predicated upon simultaneous, interchangeable attacking, and defensive stances. This can be appreciated in most traditional and contemporary martial arts, such as Wing Chun (Cheng 1986) and Krav Maga (Ben Keren 2014). It was also remarked upon in medieval and post-medieval European fencing manuals (e.g. Liechtenauer's MS Chart.A.558 from 1443). In the latter, certain common engagements are referred to as a Meisterhau (master strike), which is meant to attack and defend simultaneously (wiktenauer.com). Instead of offensive and defensive stances exchanged by the fighters in turn, the historic sources agree in suggesting that

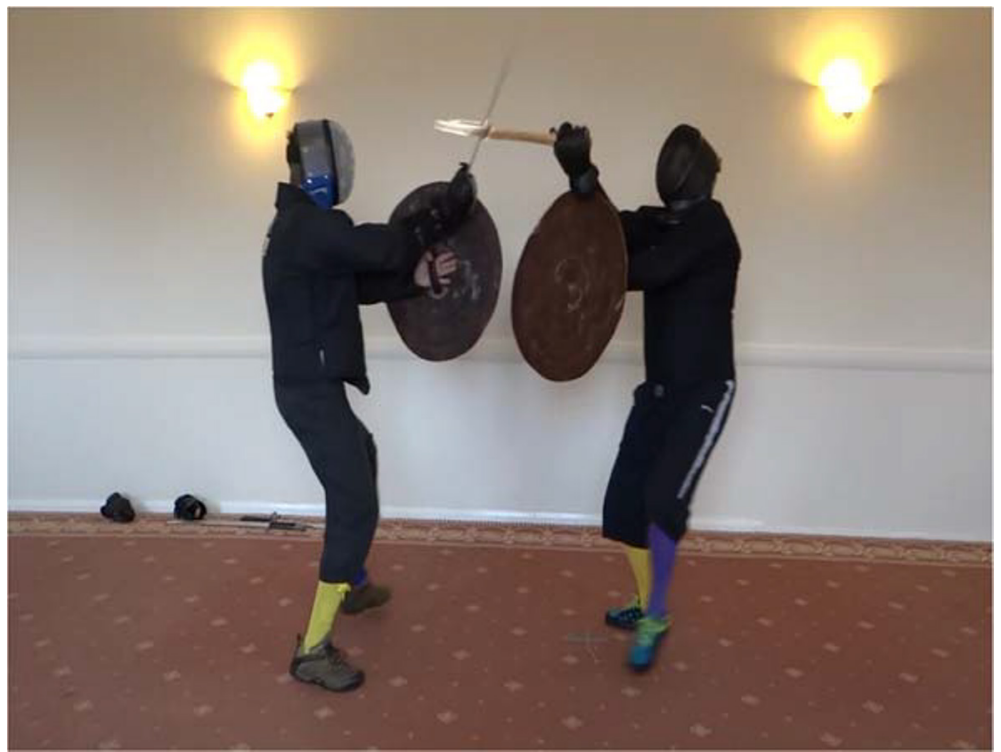

Fig. 10 Actualistic weapon test 304b: the defender binds the swords to control the opponent's blade. This caused a distinctive bulge in the cutting edge of the attacking sword 

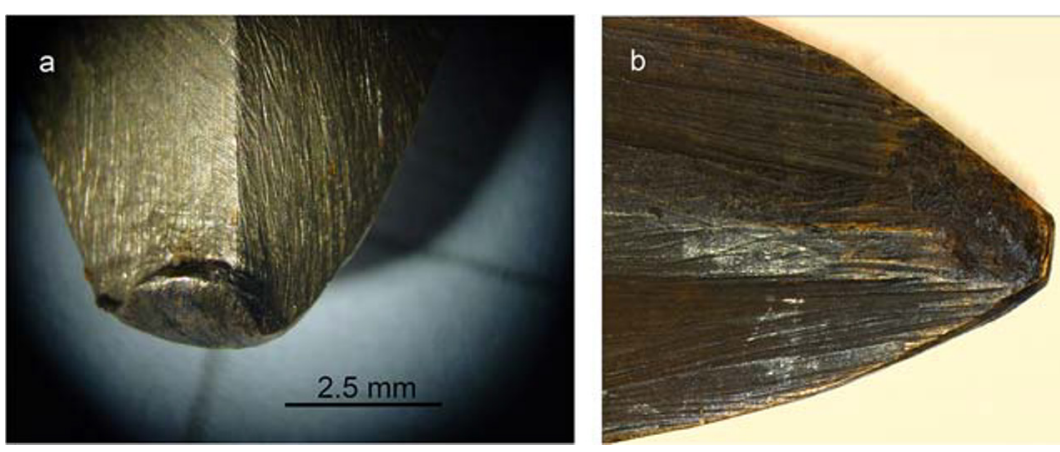

Fig. 11 a Replica tip pressure from test 104b. b Archaeological tip pressure on sword ID 5

swordplay consists of offensive actions that simultaneously defend and prime the weapon for the next attack.

This notion bears significant implications for the interpretation of our experimental and archaeological wear marks. None of the marks created during the AWTs, which better reflect actual swordplay, can exclusively be classed as offensive or defensive. This includes notches, bulges, grazes, flattenings, and striations (Table 5). Although this is partly a function of the historic fencing style adopted for the experiment, it is notable that other experiential sword tests have generated similar results using different protocols and weapon types (e.g. Gentile and van Gijn 2019). To some extent, this is also true of our controlled tests. Although we clearly separated out attacking and defending weapons in the CWTs, certain wear marks (though not all: see Table 5) were created on both swords. This provides an important behavioural interpretation for the archaeological wear marks, suggesting that notions of mutually exclusive attacking and defending actions, as well as the view that certain sections of the blade would primarily be used for either (e.g. Kristiansen 2002: 323), should be rejected.

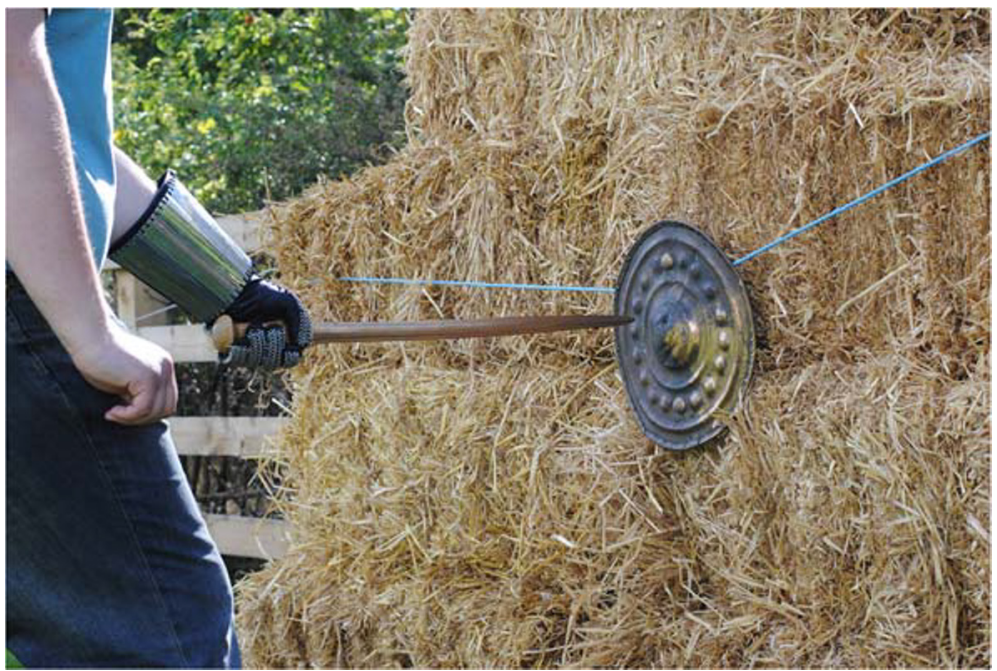

Fig. 12 Controlled weapon test 104a: static sword thrust to the face of the bronze shield mounted on hay bales 


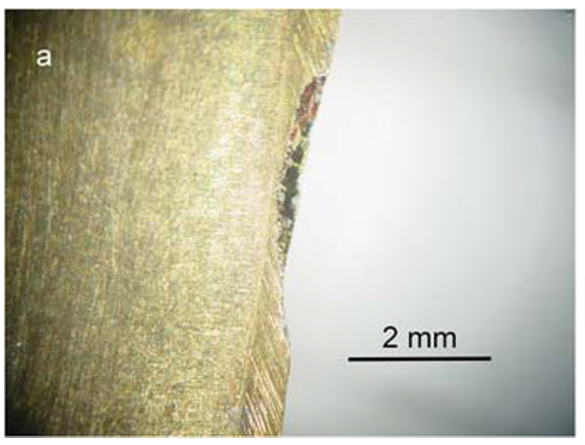

b

$\underline{1 \mathrm{~mm}}$

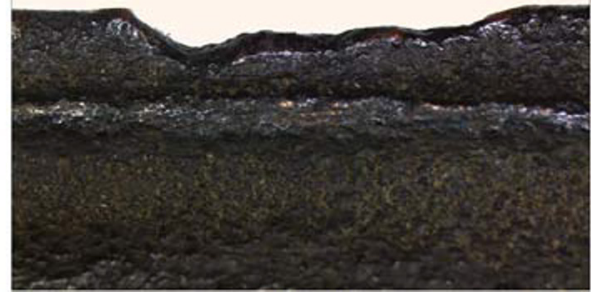

Fig. 13 a Replica irregular graze from test 201b. b Archaeological irregular graze, mark ID 186

Interestingly, while popular-culture ideas of swordplay are predicated upon clearly defined weapon exchanges, students of prehistoric fencing have suggested that fighters would avoid blade contact as much as possible to limit damage to their weapons (Molloy 2017: 288). This is due to the higher ductility and (generally) lower hardness values of tin bronze compared to steel, which would cause higher rates of damage on prehistoric swords vis-à-vis historic bladed weapons (Wang et al. 2016). While our experiments have demonstrated that violent clashes would likely disable bronze swords (see 'Diagnostic Combat Marks'), they have also shown that bulges, which are found regularly on archaeological swords, are caused by low-velocity blade-on-blade impacts. As discussed above, bulges provide prima facie evidence of binding and twisting motions; they are created when a sword is intentionally connected with the opponent's blade to stifle and control it. Marks other than bulges were also created by deliberate low-velocity impacts with the opponent's weapons (Table 5). Overall, the evidence indicates that Bronze Age fighters would have accepted a small amount of wear to their

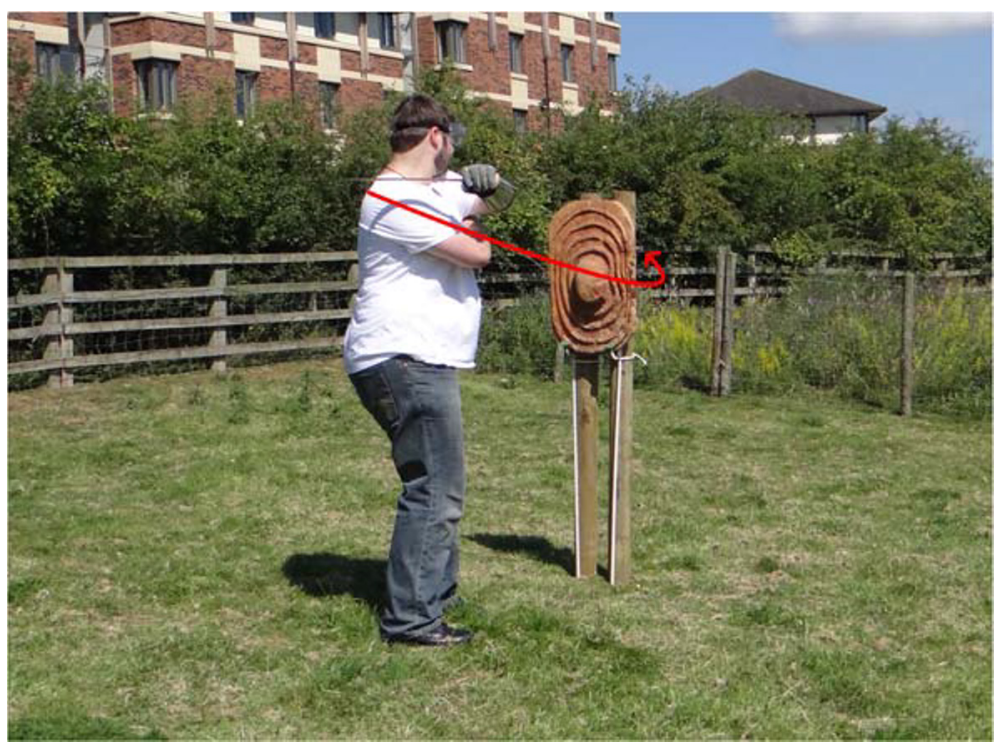

Fig. 14 Controlled weapon test 201b: glancing sword blow to the face of the wooden shield. This caused an irregular graze in the cutting edge 


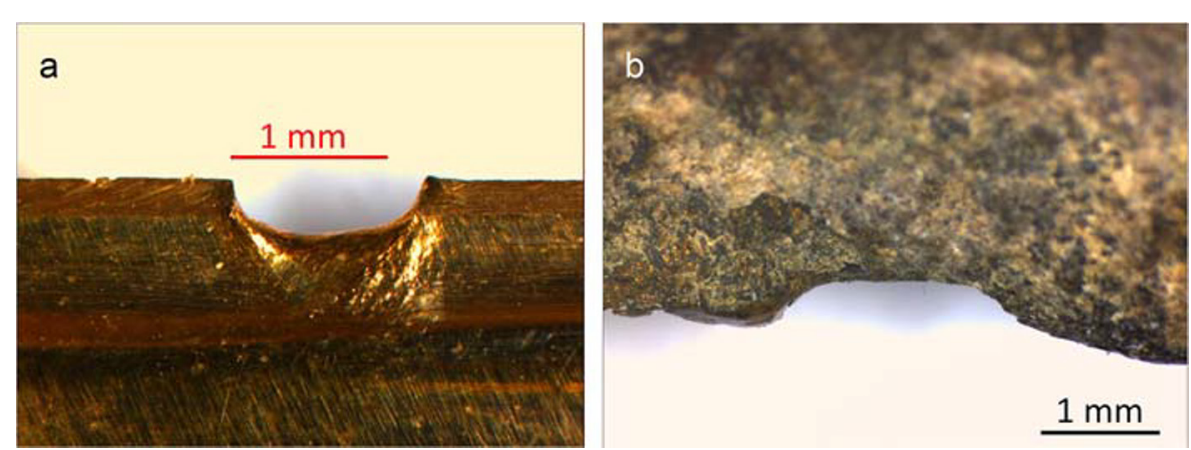

Fig. 15 a Replica rectangular indentation from test 36a. b Archaeological rectangular indentation, mark ID 216

blades in order to bind the opponent's. Hence, most marks found on prehistoric swords should not be interpreted as accidental (Horn 2013: 40), but rather as the result of distinctive fighting styles favouring close-quarter engagement and involving deliberate blade contact. This is underscored by the HEMA swordfighters' observation that, due to their material properties, bronze swords tend to 'stick together' as they meet, making blade-controlling moves easy to practise (see 'Bulge'). Furthermore, the geometry, balance, and relative shortness of most Bronze Age swords indicate that these weapons had been designed for close-range engagements. Taken together, the archaeological, analytical, and experimental data contribute a strong case for prehistoric swordsmanship being a contact martial discipline involving a certain amount of wilful, skilfully controlled blade contact. This is not something that one could improvise. As was the case in later times, mastering sword-twisting and binding techniques would require initial guidance and regular follow-up practice-in other words, structured weapon training.

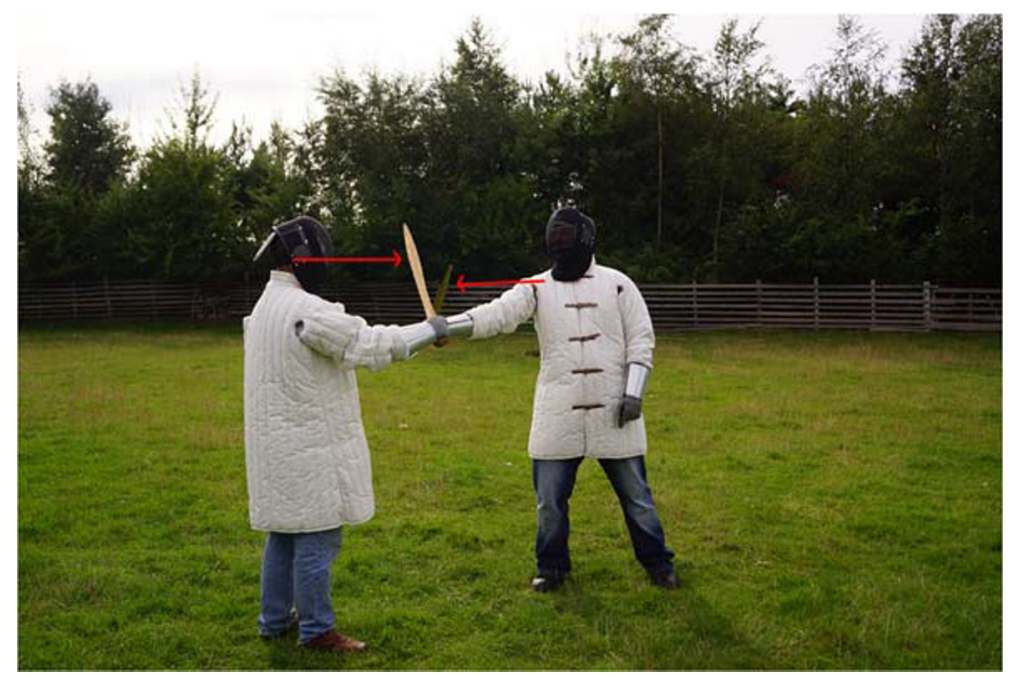

Fig. 16 Controlled weapon test 36a: shoulder strike vs static edge parry. This caused a rectangular indentation in the attacking sword 


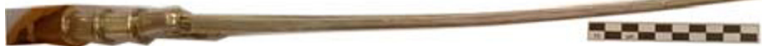

Fig. 17 Replica sword used in controlled weapon test $01 \mathrm{k}$. Note the $10^{\circ}$ curvature from the original weapon axis

\section{Bent Swords, Straight Swords, and Target Areas}

The damage pattern discussed in 'Diagnostic Combat Marks' suggests that Bronze Age swords were not suited for hard blocks executed with the flat of the blade. This view is supported by the wear analysis of archaeological swords, revealing that only four specimens (out of 110) had sustained comparable blade damage. This ties in with the broader archaeological record (Horn 2013; Mödlinger 2011a, b; Molloy 2007, 2010, 2011, 2017, 2018; see also Burgess and Colquhoun 1988). The bending of swords has been discussed by Kristiansen (2002). He argues that prehistoric swords were often deliberately bent by fencers so that the blade tip would point towards the opponent's heart. He grounds his proposal in an analogy with modern fencers who, he claims, would bend the tips of their swords in a similar fashion (Kristiansen 2002: 320).

This reading presents several problems. Firstly, bending the blade to point at the opponent's heart implies that early swords were primarily used as thrusting weaponsan argument disproved by a wealth of research on prehistoric swordsmanship, as well as our experiments (Anderson 2011; Knight 2019; Molloy 2007, 2008; Gentile and van Gijn 2019). Furthermore, experience shows that thrusting with a bent sword is dangerous and ineffective, as it inhibits fine control of the weapon and makes it hard to predict where the point would hit the target. Conversations with HEMA specialists support the view that double-edged swords lose functionality if the point is bent. Although he does not say, we presume that Kristiansen's proposal is based on a conversation with a foil fencer. Modern foil blades consist of thin, wire-like steel bands which significantly bend under pressure and are exclusively used for thrusting (British Fencing 2017: 10). These blades are deliberately bent downwards to prevent the tip from sliding under the opponent's mask. The slight bend also assists in reaching around the opponent's arms to hit the target, which, in this fencing discipline, is limited to the upper body (Fig. 28). Contemporary foil fencing, however, provides a poor analogy for prehistoric swordsmanship as bronze swords feature radically different designs, balances, and material properties to foils.

A further problem with the foil fencing analogy is the implication that prehistoric sword fighters would mainly have targeted the chest. This is partially contradicted by the osteological evidence, showing that the skull and pelvis were hit more often than the chest (see Hermann 2018, 30-34; Mödlinger 2011b, 88-92, for review). Although certainly biased, as it does not account for soft-tissue injuries, the evidence is in line with what we know about sword combat cross-culturally. It is often remarked that targeting the chest in a thrusting attack carries the risk of trapping the weapon in the ribcage or sternum (Molloy 2007: 101). This area, moreover, is frequently protected by armour. Instead, sword fighters would target primarily soft body parts that (a) provide

Fig. 18 Archaeological sword ID 71. Note the $10^{\circ}$ curvature similar to Fig. 17 

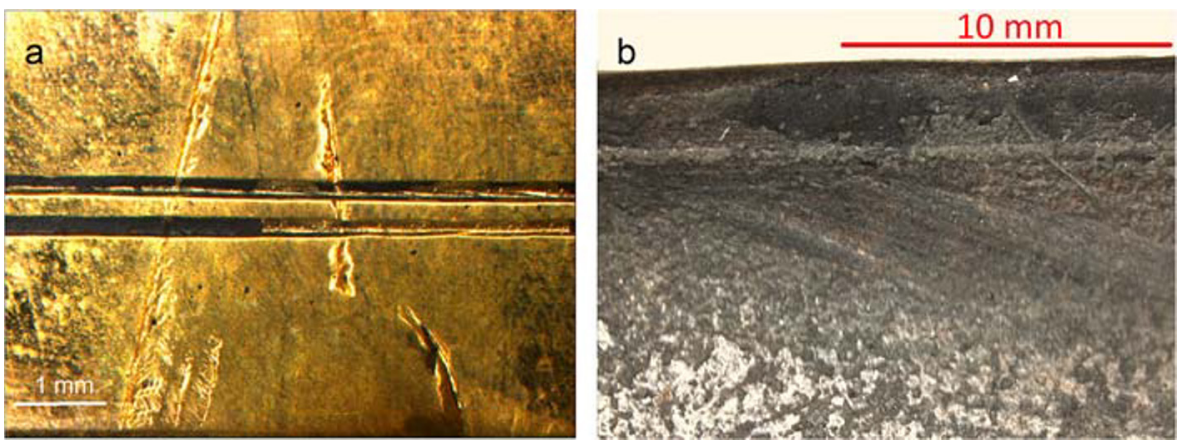

Fig. 19 a Striation patterns on the flat side of the blade (replica sword) caused in CWT 01 k (Fig. 20). b Striation patterns on the flat side of the blade of archaeological sword ID 71, near the curvature

an easy entry towards major blood vessels and/or life-supporting organs and (b) are most difficult to protect with armour. These are the neck and abdomen/pelvis. Notwithstanding the instances of broken sword (and spear) points lodged in bone (Bennike 1985: 109-10; Bóna 1975: 150; Knight et al. 1972), it seems likely that Bronze Age fighters would have predominantly aimed their thrusting attacks at the neck and abdomen/pelvis, plunging their weapons into the flesh at an angle in order to cause major blood loss and severe incapacitation, while minimising the risk of the sword getting stuck in a bone. Depictions of sword fights on Minoan and Mycenaean gem stones, such as the Pylos Combat Agate (Stocker and Davis 2017; see also Molloy 2010: 409-12), illustrate this point with graphic intensity (Fig. 29). Although these are idealised images reflecting the heroic symbolism of a lightly armed, near-defenceless fighter defeating a heavily armoured foe, they are likely grounded in the grisly realities of Bronze Age interpersonal violence.

Other combat stances would have aimed at different body parts. Molloy (2007, 2008, 2017) points out that nearly all Bronze Age swords are suitable for both stabbing

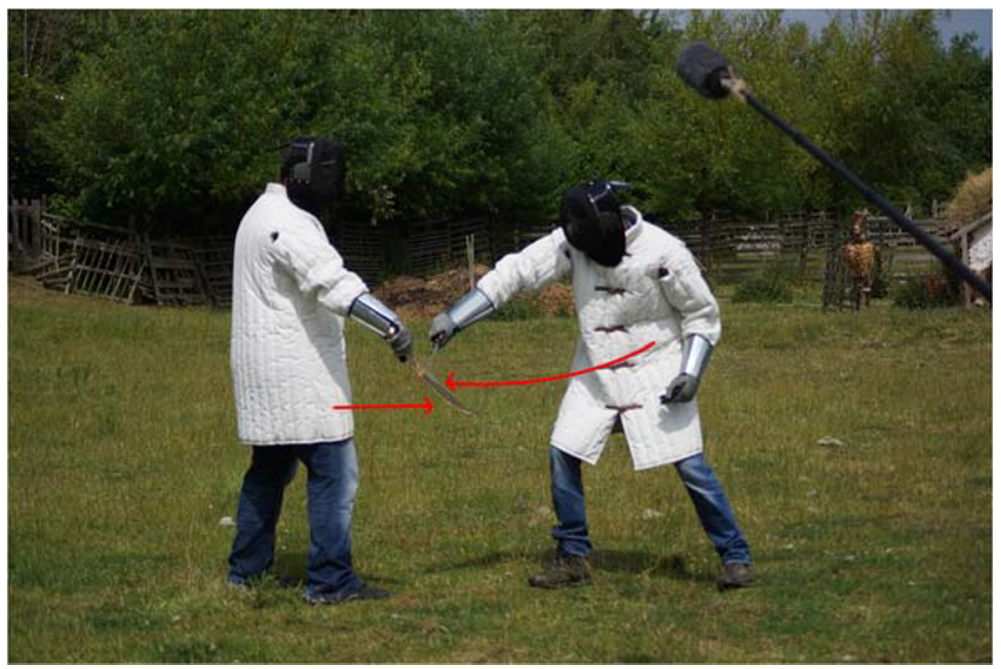

Fig. 20 Controlled weapon test $01 \mathrm{k}$ : leg strike vs dynamic flat parry. Note the defending sword (a Vollgriffschwert with wide leaf-shaped blade and narrow midrib) being bent by the incoming strike 


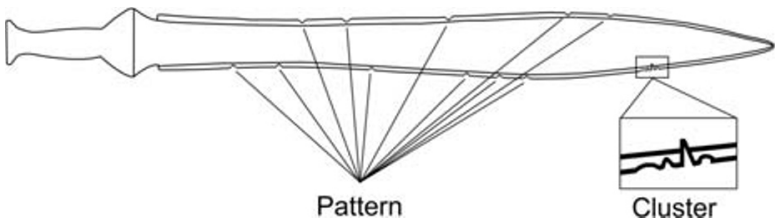

Fig. 21 Schematic drawing of a sword displaying a pattern (of one mark type) and a cluster of four (in this case four different mark types)

and cutting attacks. However, the novel features introduced towards the end of the period, namely the full hilt and leaf-swelling of the blade, as well as the bias towards longer and heavier swords with more forward-shifted points of balance, would have made cutting strikes more effective and, therefore, more likely to be attempted. Based on comprehensive combat experiments, Molloy argues that deep cutting could be achieved by drawing the blade along the target in a smooth and controlled manner, rather than swinging it in a percussive axe-like strike. Such draw-cuts would have sliced through muscles and tendons, causing blood-letting and limb incapacitation. Osteological evidence of blade cuts to the arms and legs suggests that, indeed, Bronze Age fighters would have targeted the limbs in their slashing attacks, occasionally causing the opponent's death through bleeding or intervening sepsis (Canci et al. 2005; Mödlinger 2011b: 88-89). Even when they were not lethal, deep cuts to the limbs would have impacted significantly on the dynamics of a melee fight, as one cannot fight with a disabled arm or leg, and their screams would conceivably have had a demoralising effect on their comrades. The head was also targeted by cutting and slashing strikes. This is demonstrated by several skull injuries in the osteological record and is further underscored by experimental research showing that even relatively light and short bronze swords are capable of inflicting wide incisions to synthetic analogues of human skulls (Canci et al. 2005; Downing and Fibiger 2017; Mödlinger 2011b, 8992). Overall, injury patterns and experimental evidence show that, if held by proficient fighters, prehistoric swords were extremely effective weapons for close-range combat, and could be used for thrusting as well as cutting and slashing stances (Clements 2007; Molloy 2007). This contradicts earlier arguments that these objects would be too small and flimsy to be useful on the field of battle or that they would be primarily suited to either cutting or thrusting depending on weapon design and hilting technology (Burgess and Gerloff 1981; O’Connor et al. 1995; Osgood 1998: 13).

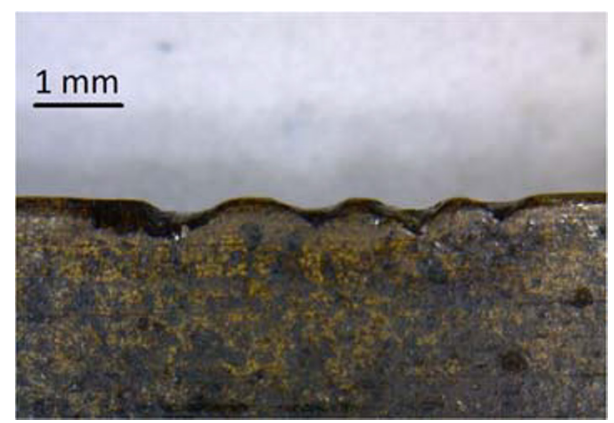

Fig. 22 Cluster of four marks (from left to right: round notch, round notch, sharp notch, sharp notch) on the right cutting edge of Sword ID 60 
Table 6 Clusters of two, three, four, and five marks found on the sample of 110 Bronze Age swords from Britain and Italy analysed for this study

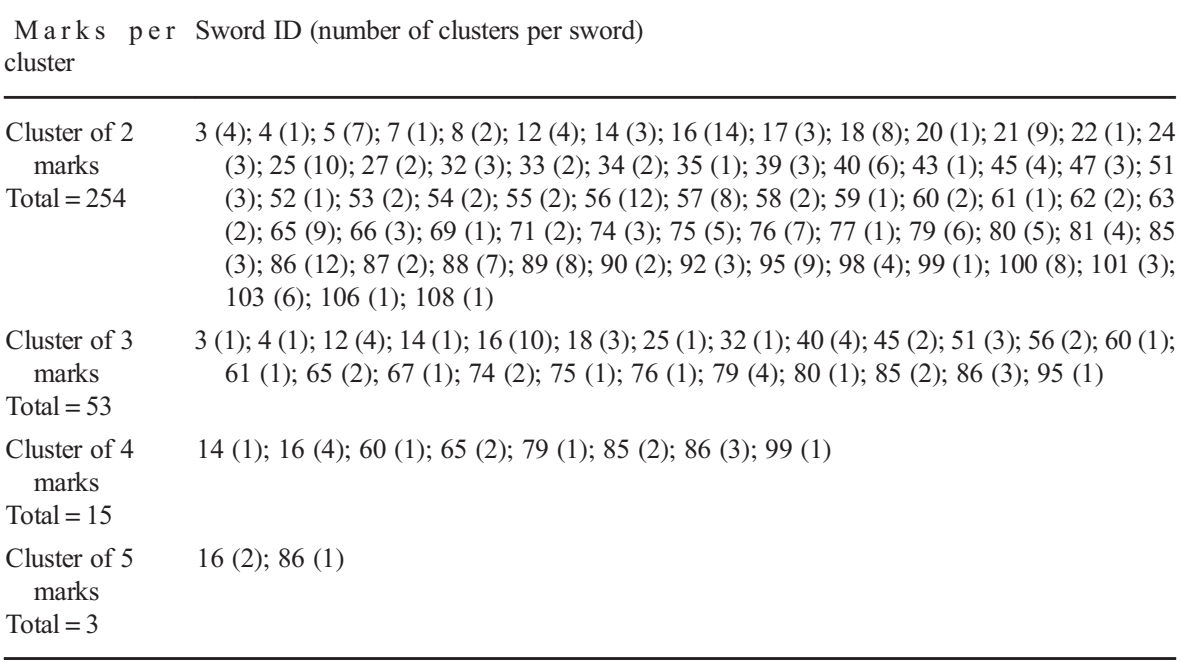

\section{The Evolution of Bronze Age Swordsmanship: Spatial and Temporal Trends}

As argued in 'Patterning and Clustering of Wear Marks', the patterning and clustering of sword combat marks over time and geography can be used to illuminate the development of fighting styles in the European Bronze Age. Arguably, mark patterns and clusters contain higher quality information about prehistoric fighting styles than individual marks. This is because they are generated by repetitive, normative actions grounded in prolonged engagement with the weapon, muscle memory, and the mental and physiological changes caused by martial training and practice (Malafouris 2008; Melheim and Horn 2014; Molloy 2008; Warnier 2011). Fighting styles, we posit, emerge from the historically contingent nexus of cultural, physical, and neurological transformations brought about by sustained weapon engagement. While this is broadly
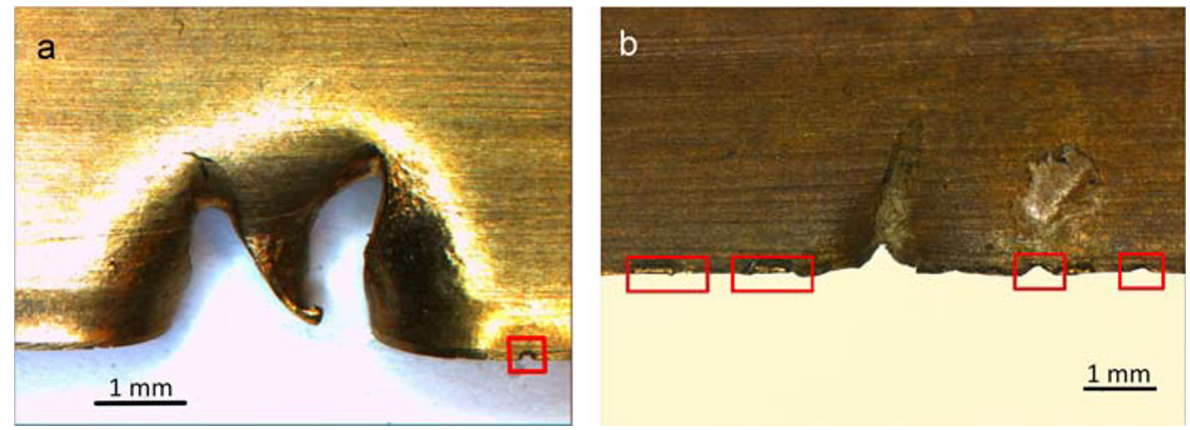

Fig. 23 Primary impact marks surrounded by smaller micronotching. a Cluster of two sharp notches and one micronotch (red) created during CWT 36b, as the result of a rebounding impact. The right sharp notch was the result of CWT 3f. b Archaeological micronotching (red) surrounding a primary sharp notch, mark IDs 119 (primary mark), 117, 118, 120, 121 (micronotching) 


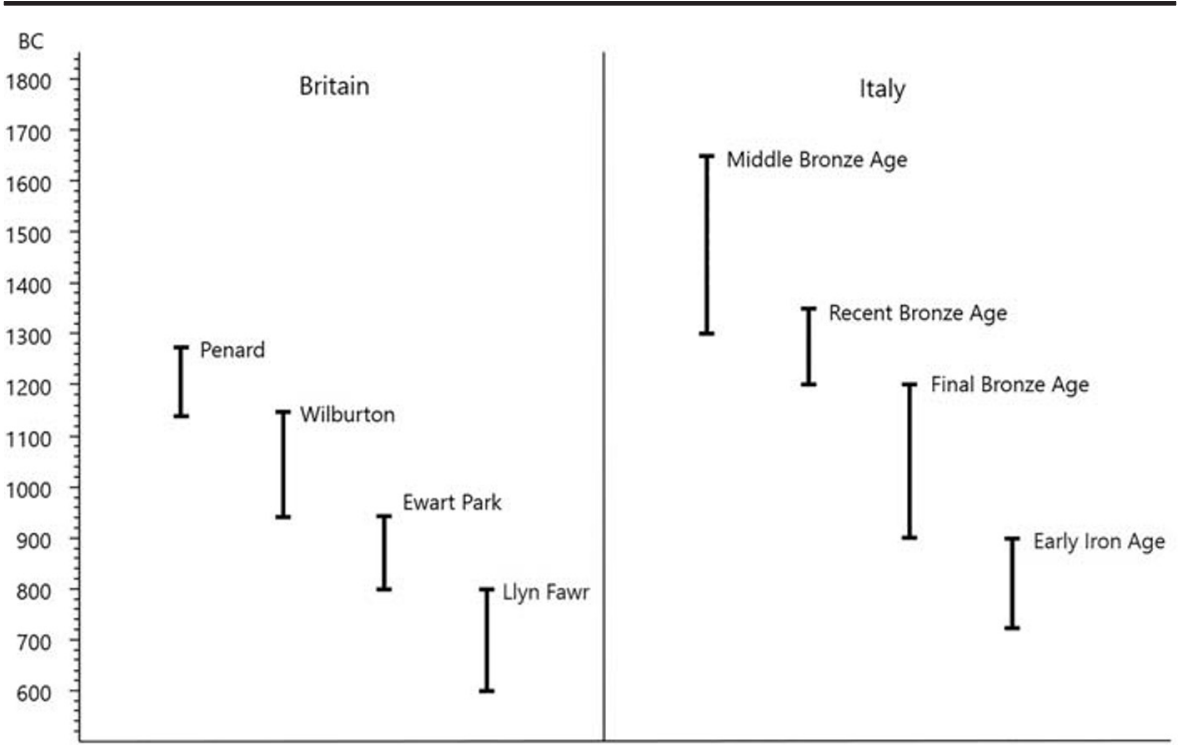

Fig. 24 Chronology of British metalworking stages and north Italian chronological sequencing from the Middle Bronze Age to the Early Iron Age. Absolute chronologies after Roberts et al. (2013) and Nicolis (2013)

true of all weapons (and all societies), certain weapons are more conducive than others to generating contingent fighting styles, as they may require lengthy training or advanced skilled practice to be operated effectively. This, we maintain, was the case with Bronze Age swords, as their proficient handling was predicated upon fine motor skills and long-term familiarity with the weapon (Molloy 2017).

The data presented in 'Patterning and Clustering of Wear Marks' indicate that British swords of the Penard Phase lack distinctive mark patterning and clustering. We interpret this as the result of a yet immature martial tradition. Although Penard Phase swords would have been used skilfully to preserve the cutting edge and point, avoid undue blade damage, and strike at the opponent before being struck by them, swordsmanship at this time would not have involved repetitive moves internalised through combat routines. This seemingly changed in the Wilburton and Ewart Park Phases, when noticeable shifts in mark location, and their denser clustering, speak for the emergence of a fencing style featuring combat actions that were routinely executed, in broadly similar ways, by multiple sword fighters. In particular, the bulges frequently observed on swords from these phases suggest that the new combat style centred on the desire to control the opponent's weapon through binding techniques akin to those carried out in the late Middle Ages. Intriguingly, a similar shift towards more frequent slashing attacks and finer blade control was observed on a sample of 304 Danish swords from periods II (c. 1500-1300 BC) and III (c. 1300-1100 BC) of the Nordic Bronze Age (Kristiansen 1984: 189-95; absolute chronology after Olsen et al. 2011: 267-8). This independently validates the results discussed here.

The picture changed yet again in the Llyn Fawr Phase, marking the transition to the Iron Age. The recurring mark patterns and clusters created by the previous martial practices disappeared. These were replaced by combat marks that are evenly spread 

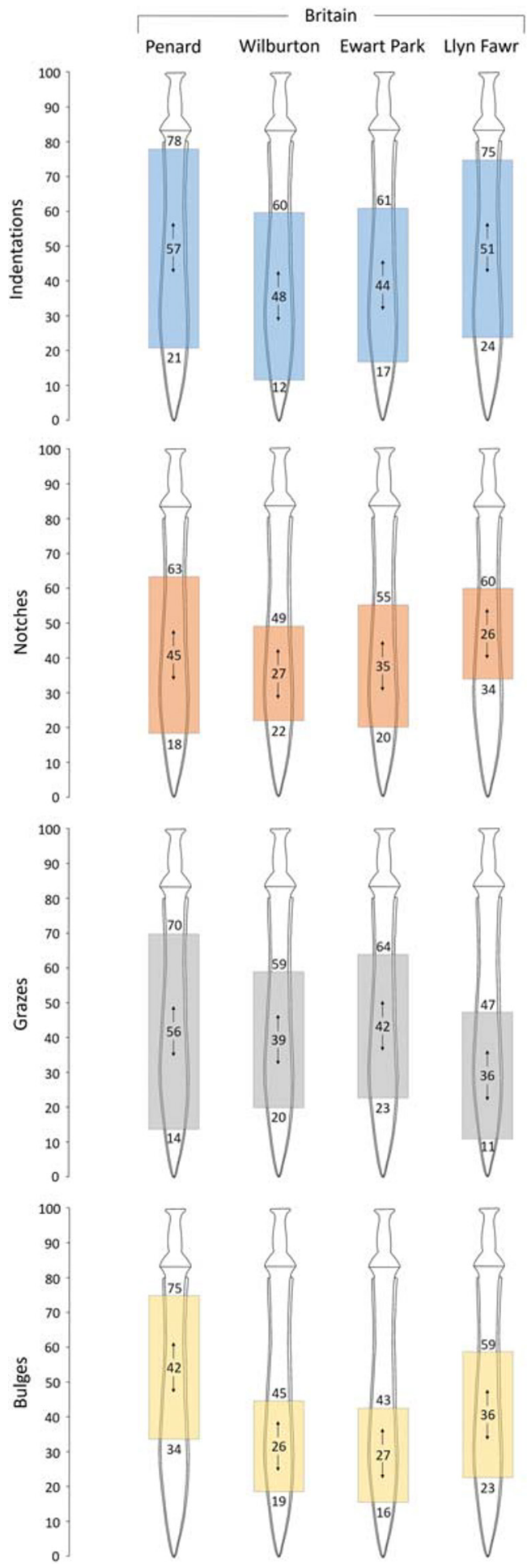
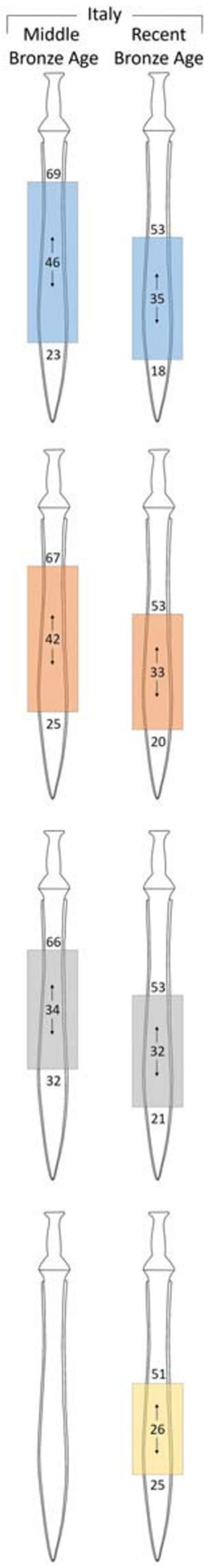
Fig. 25 Normalised distances of indentations, notches, grazes and bulges on swords from the British Penard, Wilburton, Ewart Park and Llyn Fawr phases, and the Italian Middle and Recent Bronze Age. Each sword displays the first and third quartile as well as the interquartile range

along swords blades, in a manner that is not too dissimilar to Middle Bronze Age swords. It is not clear what might have caused this apparent loss of established fighting routines. The change could perhaps be ascribed to the introduction of iron swords, which would have upended time-honoured combat practices. Another factor to consider is the growing importance of equestrian warfare in the early 1 st millennium BC (Anthony and Brown 2011; Drews 2004; Howard 2011), which would have led to new developments in weaponry (e.g. longer swords) and fighting techniques. These are questions for future experimentation and research.

Interestingly, Italian swords present us with similar trends and developments. As with their British counterparts, Italian swords display a noticeable increase in mark clustering in the Recent Bronze Age. This may be due to the introduction of sophisticated fighting practices relying on sustained weapon training and the repetition of internalised gestures. On most swords, the marks are grouped around the leaf-swelling of the blade (i.e. about one-third from the blade tip), which, in itself, is a distinctive morphological development dating to this time. We maintain that this is not a chance occurrence, for advancements in sword design and fighting practices are intimately connected. Molloy $(2007,2017)$ argues that the leaf-shaped curvature of Late Bronze Age swords (and their growing weight, which shifted the point of balance further towards the tip) enabled blades to cut deeper into the flesh as they were drawn along exposed body parts. While draw-cuts would have been practised with earlier swords, too, the new blade geometry and balance made such strikes more effective and, therefore, more desirable and common. This ties in neatly with the wear data gathered in our research: as many attempted draw-cuts would hit amour, or be deflected before they could bite into soft tissue, marks would be left on the blade swelling in evergrowing numbers.

Another feature of Italian Recent Bronze Age swords is the appearance of bulges. As discussed above, this mark type can be ascribed to a fencing technique that seeks to bind the opponent's blade not only to prevent injury but also to control it in such a way that their attack could be countered with a quick twist of the blade. The trend is clearer

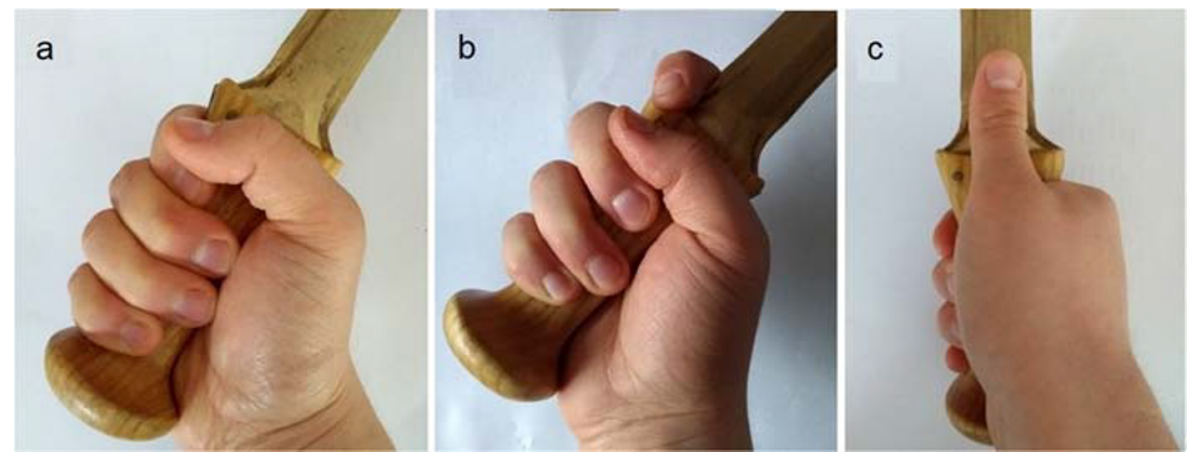

Fig. 26 How to hold a Bronze Age sword: a 'hammer grip' with the hand locked into place by the shoulder and pommel; b 'sabre grip' with the index finger curled around the ricasso; c 'thumb grip' with the thumb pressing on the flat of the blade 

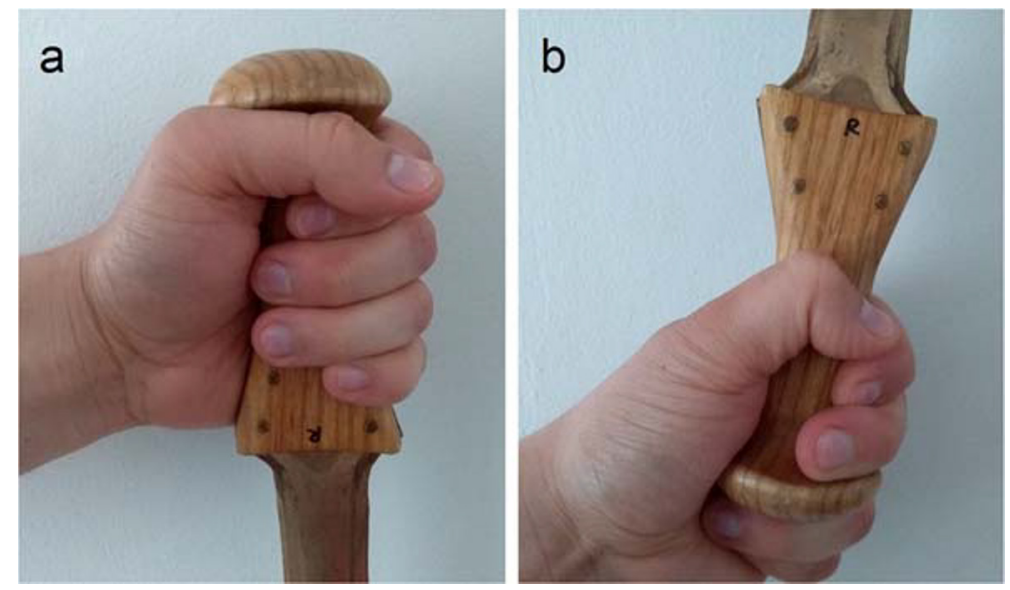

Fig. 27 How to hold a Bronze Age sword (continued). a Reverse sword grip. b Pommel grip

in Italian swords (as no bulges are recorded in the Middle Bronze Age record) than in British swords, where bulges are found on weapons from all periods including the Middle Bronze Age Penard Phase. The difference, however, is entirely due to the vagaries of archaeological terminology in the two regions, as the Italian Middle Bronze Age, c. 1650-1300 BC, precedes the British Penard Phase; this, in turn, is roughly contemporary to the Italian Recent Bronze Age (Fig. 23). Based on this consideration, we propose that fencing styles would have grown in sophistication and complexity in similar ways, and in a broadly contemporary fashion, in most of Europe. By about $1350 / 1300 \mathrm{BC}$, they would have featured blade twisting and binding moves aiming to control the opponent's weapon. In regions where fully fledged swords made their appearance around this time, such as Britain and Ireland, the new weapon would have been used from the outset with the mature martial techniques that presumably accompanied its introduction.

It is unfortunately impossible to chart the development of fighting styles in Final Bronze Age and Early Iron Age Italy (roughly contemporary to the British Wilburton, Ewart Park, and Llyn Fawr phases; Fig. 23) due to the small number of swords examined in this study. Future research will doubtless clarify if the introduction of iron weapons and equestrian warfare brought about similar changes in this region as in Britain. We presume, however, that this should be the case, considering that British and Italian swords display similar wear marks and similar trends in trace patterning and clustering over time. The one notable exception is the tendency of Italian combat marks to be smaller than those on British swords. It is presently unclear why this should be so. Differences in alloy composition and work hardening might be a factor (Gutiérrez-Sáez and Martin-Lerma 2015), as well as — but this seems less likely — differences in the amount of force applied by the combatants while fencing. This, too, is a problem for future research.

\section{Conclusion}

The article has discussed results of the experimental sword testing and wear analysis conducted by the authors from 2013 to 2018, as part of the Bronze Age Combat Project. 


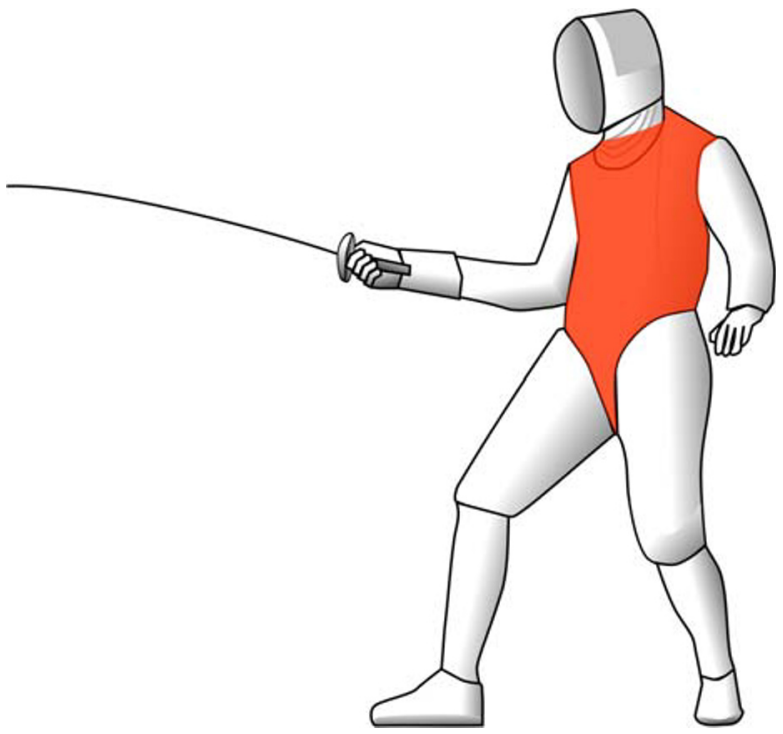

Fig. 28 Foil fencer holding a downward-bent foil; the target area is marked in orange (www.wikipedia.org)

The research has yielded original results that significantly contribute to our understanding of sanctioned violence and warfare in Middle and Late Bronze Age Europe, $c$. 1650-600 BC.

A first set of results concerns the approaches and methods utilised by these authors to researching prehistoric swordsmanship. Following the principles of experimental archaeology, we designed a wide array of controllable imitative experiments to generate and test hypotheses regarding the uses of swords and shields in Bronze Age combat

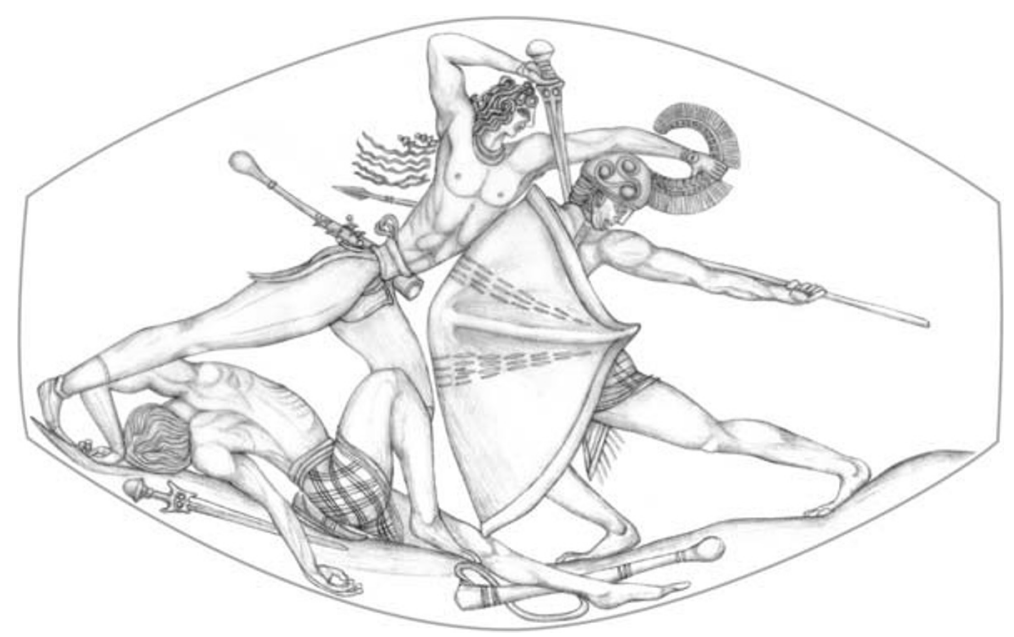

Fig. 29 Composite drawing of the Pylos Combat Agate showing two warriors engaged in close-quarter combat. The winning male on the left is plunging his sword into the opponent's neck, having twisted it over the shield. Note the sword bearer's 'hammer grip' enabling swift moves and rapid changes of direction (Stocker and Davis 2017) 
practices (Mathieu 2002: 1). Unlike previous research on the subject, however, we grounded our experimentation in two sets of tests, which were guided by differing underlying principles and methods: controlled weapon tests (CWTs), in which we separated fluid combat actions into their most elemental components (e.g. a single strike or parry), and actualistic weapon tests (AWTs), in which HEMA fighters tested the capabilities of the weapons in experiential combat sequences grounded in historic specialist knowledge. Such a hybrid approach allowed us to break down the somewhat artificial barrier separating functional and phenomenological weapon studies (Dolfini and Collins 2018), enhanced the strengths of both types of experiment while minimising their weaknesses, and provided a reflexively generated dataset to interpret the combat marks visible on archaeological Bronze Age swords from Britain and Italy. Importantly, the replica weapons used in our experiments were built by skilled craftspeople, and their material properties and performance characteristics were assessed by scientific analysis. This has ensured consistency in the interpretation of experimental and archaeological wear marks. Overall, this interdisciplinary research strategy has allowed new knowledge to arise at the nexus between controlled experimentation, experiential weapon testing, and the validation of experimental results by metalwork wear analysis.

A second set of results concerns the new knowledge and understanding of prehistoric swordsmanship generated by the project. Firstly, the research has identified several types of diagnostic and undiagnostic combat marks on prehistoric bronze swords and has interpreted them in light of the experimental tests. This has fulfilled, if perhaps partly, one of the project's main objectives, which was to link distinctive combat marks with specific uses of the weapons. Secondly, it has elucidated how Bronze Age swords may have been held and operated, and the degree of skill and training required in their proficient handling. Thirdly, it has overturned previous assumptions concerning the alternating attacking and defending stances that - it is often posited - would characterise prehistoric swordplay, while also disproving scholarly claims that early fencers would avoid blade-on-blade contact to preserve their weapons. On the contrary, the research has demonstrated that Bronze Age fighters would deliberately seek contact with their foes' swords in order to stifle and control them. Not only is this a significant advance in its own right, but it also provides a convincing explanation for the plethora of wear marks found on archaeological swords, as well as much-needed analytical diagnostics for discriminating between combat and deliberate destruction marks (see also Knight 2019). Fourthly, the research has disproved suggestions that early sword fencers would intentionally bend the tips of their swords to hit their opponent's heart and contributed new knowledge about the body parts most often targeted by sword thrusts and cuts. This ties in with previous experimental research and osteological analysis (Canci et al. 2005; Downing and Fibiger 2017; Mödlinger 2011a, b; Molloy 2006, 2007, 2008). Finally, it has provided a compelling narrative regarding the evolution of fighting styles in late 2 nd and early 1st millennia BC Europe, which integrates, and elevates, other authors' insights (Molloy 2007, 2017).

Perhaps the most important result of the research is to have provided an innovative, methodologically sound blueprint for investigating early weapons and combat styles, which could be applied to other regions, periods, and weapon types in prehistoric Europe. The research has also highlighted two outstanding issues which future studies 
ought to address. Firstly, the extent to which the experimental and analytical results generated by different teams can be compared with one another. As the study of early weapons keeps growing in size and sophistication, this is emerging as a key issue hindering disciplinary progress. The strategy that these authors have adopted, which relies on a clearly defined wear mark terminology, explicit methods and protocols for testing replica weapons, and the complete publication of experimental and analytical results, offers a way out of the problem. A second issue concerns the relevance of early weapon and combat studies - a rather specialised research strand - for the broader field of European prehistory. Here, the answer comes from the many unexpected insights that the research has provided into burning issues in social archaeology including craftsmanship, apprenticeship, and skill (Kuijpers 2018a, 2018b). While their indepth discussion lay outside the scope of this paper, the data and interpretations presented in these pages show clear potential for addressing these problems from a new angle. In this respect, too, the Bronze Age Combat Project has supplied a robust scaffold to which fresh research on prehistoric society could be anchored.

Acknowledgements We wish to acknowledge the many institutions and friends who supported the Bronze Age Combat Project. We thank Newcastle University and The British Museum for generously funding the replica weapons and experiments; the Historical Metallurgy Society for financial support to undertake the research trip to Rome; Neil Burridge and Jake Newport for skilfully making the swords, spears, and shields used in the combat tests; Bede's World Museum (now Jarrow Hall) and Durham University Botanic Garden for hosting the tests; Jon Allison and Kate Anderson for contributing to the controlled weapon tests; HEMA fighters Robert Brooks and Andrew Milburn (Hotspur School of Defence) for advice on interpreting Lignitzer's Commentary and conducting the actualistic weapon tests; Amber Roy for constructive criticism of the manuscript; Laura Hermann for proofreading; The British Museum, Great North Museum: Hancock, The Museum of London, Alnwick Castle and Garden, Preston Park Museum, the Yorkshire Museum of Archaeology, the Soprintendenza Archeologica, Belle Arti e Paesaggio per le Province di Verona and the Museo Nazionale Preistorico Etnografico 'Luigi Pigorini' for liberally granting access to their archaeological sword collections; David Horan and Geoff Lowe for expert photography and filming; and Thea Ravasi for project website design and logistics.

Funding Information Open Access funding provided by Projekt DEAL. The project has received research funding from Newcastle University and the British Museum.

\section{Compliance with Ethical Standards}

Disclaimer All opinions and errors are our own.

Conflict of Interest Author Raphael Hermann has received research funding from the Historical Metallurgy Society.

Open Access This article is licensed under a Creative Commons Attribution 4.0 International License, which permits use, sharing, adaptation, distribution and reproduction in any medium or format, as long as you give appropriate credit to the original author(s) and the source, provide a link to the Creative Commons licence, and indicate if changes were made. The images or other third party material in this article are included in the article's Creative Commons licence, unless indicated otherwise in a credit line to the material. If material is not included in the article's Creative Commons licence and your intended use is not permitted by statutory regulation or exceeds the permitted use, you will need to obtain permission directly from the copyright holder. To view a copy of this licence, visit http://creativecommons.org/licenses/by/4.0/. 


\section{References}

Allen, I., Britton, D., \& Coghlan, H. (1970). Metallurgical reports on British and Irish Bronze Age implements and weapons in the Pitt Rivers Museum. In Pitt Rivers occasional papers on technology, 10. Oxford: Oxford University Press.

Anderson, K. (2011). Slashing and thrusting with Late Bronze Age spears: analysis and experiment. Antiquity, 85(328), 599-612.

Angelini, I., Artioli, G. and Salzani, L. (2003). Chemical and metallographic investigation of weapons from the Bronze Age necropolis at Olmo di Nogara, Italy. International Conference: Archaeometallurgy in Europe - 24-26 September 2003, Milano, Italy. Proceedings, Vol. 2, 67-76.

Anglo, S. (2000). The martial arts of renaissance Europe. London: Yale University Press.

Anthony, D. W., \& Brown, D. R. (2011). The secondary products revolution, horse-riding, and mounted warfare. Journal of World Prehistory, 24(2-3), 131.

Avner, S. H. (1974). Introduction to physical metallurgy. London: Mcgraw-hill Book Company.

Ben Keren, G. (2014). Krav Maga - real world solutions to real world violence. Clarendon: Tuttle Publishing.

Bennike, P. (1985). Palaeopathology of Danish skeletons: a comparative study of demography, disease and injury. Copenhagen: Akademisk Forlag.

Bóna, I. (1975). Die mittlere Bronzezeit Ungarns und ihre südöstlichen Beziehungen. Archaeologia Hungaria Series 49. Budapest: Akademia Kiado.

Bridgford, S. (1997). Mightier than the pen? An edgewise look at Irish Bronze Age swords. In J. Carman (Ed.), Material harm: archaeological studies of war and violence (pp. 95-115). Glasgow: Cruithne Press.

Bridgford, S.D. (2000). Weapons, warfare and society in Britain 1250-750 BC (University of Sheffield) Unpublished $\mathrm{PhD}$ Thesis.

British Fencing (2017). Rules for competitions. Book 3: material rules. Available at http://www.britishfencing. com/governance/rules/fie-rules/ (Accessed: 02 June 2018).

Brown, M.A. and Blin-Stoyle, A. E. (1959). A sample analyses of British Middle and Late Bronze Age material, using optical spectrometry. Proceedings of the Prehistoric Society 25, 188-208, and Archaeometry 2 supplement.

Bunnefeld, J.-H. (2016). Älterbronzezeitliche Vollgriffschwerter in Dänemark und Schleswig-Holstein : Studien zu Form. Technik und Funktion: Verzierung.

Burgess, C. B., \& Gerloff, S. (1981). The dirks and rapiers of Great Britain and Ireland. Prähistorische Bronzefunde VI,7. München: C.H. Beck.

Burgess, C .B. and Colquhoun, I. (1988). The swords of Britain. Prähistorische Bronzefunde IV, 5. München: C.H. Beck.

Canci, A., Contursi, D., \& Fornaciari, G. (2005). La necropoli dell'età del Bronzo di Olmo di Nogara (Verona): primi risultati dello studio paleopatologico. In L. Salzani (Ed.), La necropoli dell'Età del bronzo all'Olmo di Nogara (pp. 495-501). Verona: Museo Civico di Storia Naturale di Verona.

Cheng, J. (1986). Wing Chun: The art of simultaneous defence and attack. Boulder: Paladin Press.

Clements, J. (1997). Renaissance swordsmanship. Boulder: Paladin Press.

Clements, J. (1998). Medieval swordsmanship. Boulder: Paladin Press.

Clements, J. (2002). How to teach an understanding of parrying - part III: the two positions. Available at http://www.thearma.org/essays/parrying3.htm\#.XUwTOHtCSUk (Accessed: 08. July 2019).

Clements, J. (2007). The myth of thrusting versus cutting swords. In B. Molloy (Ed.), The cutting edge: studies in ancient and medieval combat (pp. 168-176). Stroud: Tempus.

Crellin, R. J. (2018). Examining the British and Irish Early Bronze Age flat axes of the Greenwell collection at the British Museum. Journal of Archaeological Science: Reports, 18, 858-888.

Crellin, R. J., Dolfini, A., Uckelmann, M., \& Hermann, R. (2018). An experimental approach to prehistoric violence and warfare? In A. Dolfini, R. J. Crellin, C. Horn, \& M. Uckelmann (Eds.), Prehistoric warfare and violence: quantitative and qualitative approaches (pp. 279-305). New York: Springer.

Crellin, R.J., Dolfini, A., Hermann, R. and Uckelmann, M. (in preparation). Spearing the enemy? Results of experiments and metalwork wear-analyses on spearheads from Britain.

Dolfini, A. (2011). The function of Chalcolithic metalwork in Italy: an assessment based on use-wear analysis. Journal of Archaeological Science, 38(5), 1037-1049.

Dolfini, A., \& Crellin, R. J. (2016). Metalwork wear analysis: the loss of innocence. Journal of Archaeological Science, 66, 78-87.

Dolfini, A., Crellin, R. J., Horn, C., \& Uckelmann, M. (2018). Interdisciplinary approaches to prehistoric warfare and violence: past, present and future. In A. Dolfini, R. J. Crellin, C. Horn, \& M. Uckelmann 
(Eds.), Prehistoric warfare and violence: quantitative and qualitative approaches (pp. 1-18). New York: Springer.

Dolfini, A., \& Collins, R. (2018). Modelling physical and digital replication: bridging the gap between experimentation and experience. Open Archaeology, 4(1), 36-49.

Downing, M., \& Fibiger, L. (2017). An experimental investigation of sharp force skeletal trauma with replica Bronze Age weapons. Journal of Archaeological Science: Reports, 11, 546-554.

Drews, R. (2004). Early riders: the beginnings of mounted warfare in Asia and Europe. New York: Routledge.

Faoláin, S. Ó., \& Northover, J. P. (1998). The technology of Late Bronze Age sword production in Ireland. Journal of Irish Archaeology, 9, 69-88.

Farrell, K. (2012). Codex 44.A.8: commentary by Andre Lignitzer on sword and buckler. Glasgow: Academy of Historical Arts.

Forgeng, J. L. (2003). The medieval art of swordsmanship: a facsimile and translation of Europe's oldest Personal Combat Treatise, Royal Armouries MS I. 33. Highland Village, TX: Chivalry Bookshelf.

Forgeng, J. L., \& Kiermayer, A. (2007). The chivalric art: German martial arts treatises of the middle ages and renaissance. In B. Molloy (Ed.), The cutting edge: studies in ancient and medieval combat (pp. 153-167). Stroud: Tempus.

Fry, D. P. (Ed.). (2013). War, peace, and human nature: the convergence of evolutionary and cultural views. Oxford: Oxford University Press.

Gassmann, J., Gassman, J., \& Le Coultre, D. (2017). Fighting with the Longsword: Modern-day HEMA practices. Acta Periodica Duellatorum, 5(2), 115-133.

Gener, M. (2018). Carp's tongue swords and their use. Functional, technological and morphological aspects. In C. Horn \& K. Kristiansen (Eds.), Warfare in Bronze Age Society (pp. 155-174). Cambridge: Cambridge University Press.

Gentile, V., Sparacello, V. S., D’Ercole, V., \& Coppa, A. (2018). Martial practices and warrior burials: humeral asymmetry and grave goods in Iron age male inhumations from Central Italy. In A. Dolfini, R. J. Crellin, C. Horn, \& M. Uckelmann (Eds.), Prehistoric warfare and violence: quantitative and qualitative approaches (pp. 61-83). New York: Springer.

Gentile, V., \& van Gijn, A. (2019). Anatomy of a notch. An in-depth experimental investigation and interpretation of combat traces on Bronze Age swords. Journal of Archaeological Science, 105, 130-143.

Griswold, K. (2016). Liegniczer sword and buckler - understanding HEMA. Available at https://www.youtube.

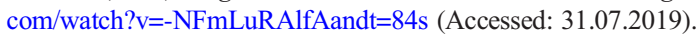

Gutiérrez Sáez, C., \& Martín Lerma, I. (2015). Traceology on metal. Use-wear marks on copper-based tools and weapons. In J. Marreiros, J. Gibaja, \& N. Bicho (Eds.), Use-wear and residue analysis in archaeology (pp. 171-188). New York: Springer.

Hermann, R. (2018). Unlocking Bronze Age combat: sword experiments and wear analysis (Newcastle University) Unpublished $\mathrm{PhD}$ thesis.

Hermann, R., Dolfini, A., Crellin, R. J., \& Uckelmann, M. (2019). Researching Bronze Age swordsmanship: experiments and wear analysis. In S. Wetzler, L. Deutscher, \& M. Kaiser (Eds.), The sword: form and thought (pp. 187-207). Martlesham: Boydell and Brewer Ltd.

Hermann, R., Crellin, R. J., Uckelmann, M., Wang, Q., \& Dolfini, A. (2020). Bronze Age combat experiments. British archaeological reports. Oxford: Archaeopress.

Horn, C. (2013). Weapons, fighters and combat: spears and swords in Early Bronze Age Scandinavia. Danish Journal of Archaeology, 2(1), 20-44.

Horn, C. (2014). Harm's way - an approach to change and continuity in prehistoric combat. Current Swedish Archaeology, 21, 93-116.

Horn, C. (2017). Die by the sword ... or the spear? Early bronze weapons in Scandinavia. In M. FernándezGötz \& N. Roymans (Eds.), Conflict archaeology - materialities of collective violence from prehistory to late antiquity (pp. 51-60). London: Routledge.

Horn, C., \& Kristiansen, K. (Eds.). (2018). Warfare in Bronze Age Society. Cambridge: Cambridge University Press.

Howard, D. (2011). Bronze Age military equipment. Barnsley: Pen and Sword.

Keeley, L. H. (1996). War before civilization. Oxford: Oxford University Press.

Kemenczei, T. (1991). Die Schwerter in Ungarn II (Vollgriffschwerter). In Prähistorische Bronzefunde IV, 9. Stuttgart: Franz Steiner Verlag.

Knight, M.G. (2019). Going to pieces: investigating the deliberate destruction of Late Bronze Age swords and spearheads. Proceedings of the Prehistoric Society 1-22.

Knight, R. W., Browne, C., \& Grinsell, L. V. (1972). Prehistoric skeletons from Tormarton. Transaction of the Bristol and Gloucestershire Archaeological Society, 91, 14-17. 
Koui, M., Papandreopoulos, P., Andreopoulou-Mangou, E., Papazoglou-Manuoudaki, L., Priftaj-Vevecka, A., \& Stamati, F. (2006). Study of Bronze Age copper-based swords of type Naue II and spearheads from Greece and Albania. Mediterranean Archaeology and Archaeometry, 6(2), 5-22.

Kristiansen, K. (1984). Krieger und Häuptlinge in der Bronzezeit Dänemarks. Ein Beitrag zur Geschichte des bronzezeitlichen Schwertes. Jahrbuch des römisch-germanischen Zentralmuseums, 31, 187-208.

Kristiansen, K. (2002). The tale of the sword: swords and swordfighters in Bronze Age Europe. Oxford Journal of Archaeology, 21(4), 319-332.

Kristiansen, K. (2018). Warfare and the political economy: Europe 1500-1100 BC. In C. Horn \& K. Kristiansen (Eds.), Warfare in Bronze Age Society (pp. 27-52). Cambridge: Cambridge University Press.

Kristiansen, K., \& Larsson, T. B. (2005). The rise of Bronze Age society. Cambridge: Cambridge University Press.

Kristiansen, K., \& Suchowska-Ducke, P. (2015). Connected histories: the dynamics of Bronze Age interaction and trade 1500-1100 BC. Proceedings of the Prehistoric Society, 81, 361-392.

Kuijpers, M. H. (2018a). An archaeology of skill: metalworking skill and material specialization in Early Bronze Age Central Europe. London and New York: Routledge.

Kuijpers, M. H. (2018b). The Bronze Age, a world of specialists? Metalworking from the perspective of skill and material specialization. European Journal of Archaeology, 21(4), 550-571.

Lull, V., Micó, R., Rihuete Herrada, C., Risch, R., \& Escanilla, N. (2017). Halberdiers and combat systems in the Argaric. Oxford Journal of Archaeology, 36(4), 375-394.

Malafouris, L. (2008). Is it "me" or is it "mine"? The Mycenaean sword as a body-part. In J. Robb \& D. Boric (Eds.), Past bodies (pp. 115-123). Oxford: Oxbow Books.

Mathieu, J. R. (2002). Introduction. In J. R. Mathieu (Ed.), Experimental archaeology: replicating past objects, behaviors, and processes (pp. 1-11). Oxford: Archaeopress.

Mauss, M. (1973). Techniques of the body. Economy and Society, 2(1), 70-88.

Melheim, L., \& Horn, C. (2014). Tales of hoards and swordfighters in Early Bronze Age Scandinavia: the brand new and the broken. Norwegian Archaeological Review, 47, 18-41.

Mödlinger, M. (2011a). Ritual object or powerful weapon - the usage of central European Bronze Age swords. In M. Uckelmann and M. Mödlinger (Eds), Bronze Age Warfare: manufacture and use of weaponry. BAR international series 2255 (pp. 153-166). Oxford: Archaeopress.

Mödlinger, M. (2011b). Herstellung und Verwendung bronzezeitlicher Schwerter Mitteleuropas. Universitätsforschungen zür prähistorischen Archäologie, 193. Bonn: Habelt Verlag.

Molloy, B. P. (2006). The role of combat weaponry in Bronze Age societies: the cases of the Aegean and Ireland in the Middle and Late Bronze Age. (University College Dublin) Unpublished PhD thesis.

Molloy, B. (2007). What's the bloody point? Fighting with Irish Bronze Age weapons. In B. P. Molloy (Ed.), The cutting edge: studies in ancient and medieval combat (pp. 90-111). Stroud: Tempus.

Molloy, B. P. (2008). Martial arts and materiality: a combat archaeology perspective on Aegean swords of the fifteenth and fourteenth centuries BC. World Archaeology, 40(1), 116-134.

Molloy, B. P. (2009). For gods or men? A reappraisal of the function of European Bronze Age shields. Antiquity, 83(322), 1052-1064.

Molloy, B. P. (2010). Swords and swordsmanship in the Aegean Bronze Age. American Journal of Archaeology, 114(3), 403-428.

Molloy, B. P. (2011). Use-wear analysis and use-patterns of Bronze Age swords. In M. Uckelmann \& M. Mödlinger (Eds.), Warfare in Bronze Age Europe: manufacture and use of weaponry (pp. 67-84). Oxford: Archaeopress.

Molloy, B. P. (2017). Hunting warriors: the transformation of weapons, combat practices and society during the Bronze Age in Ireland. European Journal of Archaeology, 20(2), 280-316.

Molloy, B. P. (2018). Conflict at Europe's crossroads: analysing the social life of metal weaponry in the Bronze Age Balkans. In A. Dolfini, R. J. Crellin, C. Horn, \& M. Uckelmann (Eds.), Prehistoric warfare and violence: quantitative and qualitative approaches (pp. 199-224). New York: Springer.

Needham, S., Ramsey, C. B., Coombs, D., Cartwright, C., \& Pettitt, P. (2015). An independent chronology for British Bronze Age metalwork: the results of the Oxford radiocarbon accelerator programme. Archaeological Journal, 154(1), 55-107.

Nicolis, F. (2013). Northern Italy. In H. Fokkens \& A. Harding (Eds.), The Oxford handbook of European Bronze Age (pp. 692-705). Oxford: Oxford University Press.

Northover, J. P. (1988). The analysis and metallurgy of British Bronze Age swords. In C. Burgess and I. Colquhoun. The swords of Britain. Prähistorische Bronzefunde IV, 5 (pp. 130-146). München: C.H. Beck.

Northover J.P. and Bridgford, S.D. (2002). The characterization of a Bronze Age weapon hoard. In P.B. Vandiver, M. Goodway and J.L. Mass (Eds), Materials issues in art and archaeology VI. Materials 
Research Society Symposium Proceedings Volume 712: 159-166. Warrendale: Materials Research Society.

O'Connor, B., Cowie, T., \& O'Neil, M. (1995). Middle Bronze Age dirks and rapiers from Scotland: Some finds old and new. Proc Soc Antiqu Scotl, 125, 345-367.

O'Flaherty, R. (2007). A weapon of choice - experiments with a replica Irish Early Bronze Age halberd. Antiquity, 81(312), 423-434.

O'Flaherty, R., Gilchrist, M.D. and Cowie, T. (2011). Ceremonial or deadly serious? New insight into the function of Irish Early Bronze Age halberds. In: M. Uckelmann and M. Mödlinger (Eds), Bronze Age warfare: manufacture and use of weaponry. BAR International Series 2255 (pp. 39-52). Oxford: Archaeopress.

Olsen, J., Hornstrup, K. M., Heinemeier, J., Bennike, P., \& Thrane, H. (2011). Chronology of the Danish Bronze Age based on ${ }^{14} \mathrm{C}$ dating of cremated bone remains. Radiocarbon, 53(2), 261-275.

Osgood, R. (1998). Warfare in the Late Bronze Age of North Europe. In BAR international series 694. Oxford: Archaeopress.

Otterbein, K. F. (1997). The origins of war. Critical Review, 11(2), 251-277.

Otterbein, K. F. (2004). How war began. College Station: Texas A and M University Press.

Outram, A. K. (2008). Introduction to experimental archaeology. World Archaeology, 40(1), 1-6.

Roberts, B. W., \& Ottaway, B. S. (2003). The use and significance of socketed axes during the Late Bronze Age. European Journal of Archaeology, 6(2), 119-140.

Roberts, B. W., Uckelmann, M., \& Brandherm, D. (2013). Old father time: the Bronze Age chronology of Western Europe. In H. Fokkens \& A. Harding (Eds.), The Oxford handbook of the European Bronze Age (pp. 17-46). Oxford: Oxford University Press.

Schenck, T. (2011). Experimenting with the unknown. In B. Petersson \& L. E. Narmo (Eds.), Experimental archaeology between enlightenment and experience (pp. 87-98). Lund: Lund University Press.

Scott, A. (1991). Metallography and microstructure in ancient and historic metals. Los Angeles: The Getty Conservation Institute.

Soriano-Llopis, I. and Gutiérrez-Sáez, C. (2009). Use-wear analysis on metal: the influence of raw material and metallurgical production processes. In: Archaeometallurgy in Europe, Proceedings of the 2nd Conference (Aquileia 2007, pp. 115-124). Milano: Associazione Italiana di Metallurgia.

Spenneman, D. H. R. (1987). On the use-wear of stone adzes and axes and its implications for the assessment of humans handedness. Lithic Technology, 16(1), 22-27.

Steele, J., \& Uomini, N. T. (2005). Humans, tools and handedness. In V. Roux \& B. Bril (Eds.), Stone knapping: the necessary conditions for a uniquely hominin behaviour (pp. 217-239). Cambridge: MacDonald Institute for Archaeological Research.

Stocker, S. R., \& Davis, J. L. (2017). The combat agate from the grave of the Griffin Warrior at Pylos. Hesperia: The Journal of the American School of Classical Studies at Athens, 86(4), 583-605.

Talhoffer, H. (2000). Fechtbuch (translated and edited by M. Rector). London: Greenhill.

The Association for Renaissance Martial Arts (2019). Medieval and Renaissance fencing terminology from the source manuals. Available at http://www.thearma.org/terms2.htm\#.XV6J33tCSUk (Accessed: 22.08.2019).

Uckelmann, M. (2011). The function of Bronze Age shields. In M. Uckelmann \& M. Mödlinger (Eds.), Bronze Age Warfare: Manufacture and use of weaponry. BAR International Series (Vol. 2255, pp. 187200). Oxford: Archaeopress.

Uckelmann, M. (2012). Die Schilde der Bronzezeit in Nord-, West- und Zentraleuropa. In Prähistorische Bronzefunde III, 4. Stuttgart: Franz Steiner Verlag.

Uckelmann, M., Crellin, R.J., Dolfini, A. and Hermann, R. (in preparation). Bronze Age shields: functional experiments and wear analysis.

Uomini, N. T. (2009). The prehistory of handedness: archaeological data and comparative ethology. Journal of Human Evolution, 57(4), 411-419.

Vandkilde, H. (2013). Warfare in northern European Bronze Age societies. Twentieth century presentations and recent archaeological research inquiries. In S. Ralph (Ed.), The archaeology of violence. Interdisciplinary approaches (pp. 37-62). Albany: State University of New York Press.

Wagner, P., \& Hand, S. (2003). Medieval sword and shield: the combat system of royal armouries MS 1.33. Highland Village: Chivalry Bookshelf.

Wang, Q. and Ottaway, B. S. (2004). Casting experiments and microstructure of archaeologically relevant bronzes. BAR International Series 1331. Oxford: Archaeopress.

Wang, Q., Uckelmann, M., Roberts, B.W. and La Niece, S. (2016). Technical study of British Bronze Age shields in the British Museum. In R. Menon, C. Chemello and A. Oandya (Eds), Metal 2016 Proceedings 
of the Interim Meeting of the ICOM-CC Metals Working Group, September 26-30, 2016, New Delhi, India (pp. 53-60). New Delhi: ICOM-CC and Indira Gandhi National Centre for the Arts.

Warnier, J. P. (2011). Bodily/material culture and the fighter's subjectivity. Journal of Material Culture, 16(4), $359-375$.

Warzecha, R. (2017) Lignitzer's first play of the buckler. Available at https://www.youtube.com/watch?v=tz6 aEFdDGi8 (Accessed: 31.07.2019).

Winslow, C. and Winslow, B. (2011). The sword and buckler of Andre Lignitzer. Available at https://www. youtube.com/watch?v=uNF1bKo0v9k (Accessed: 31.07 .2019 ).

Yun, Z. (2009). The complete Taiji Dao. The art of the Chinese sabre. Berkeley: Blue Snake Books.

Publisher's Note Springer Nature remains neutral with regard to jurisdictional claims in published maps and institutional affiliations.

\section{Affiliations}

\section{Raphael Hermann ${ }^{1} \cdot$ Andrea Dolfini $^{2} \cdot$ Rachel J. Crellin ${ }^{3} \cdot$ Quanyu Wang ${ }^{4} \cdot$ Mar- $^{-}$ ion Uckelmann ${ }^{5}$}

1 Georg-August-Universität Göttingen, Göttingen, Germany

2 Newcastle University, Newcastle upon Tyne, UK

3 University of Leicester, Leicester, UK

4 Shandong University, Jinan, Shandong, China

5 Durham University, Durham, UK 